Research Article

\title{
Experimental and Numerical Studies on Crack Initiation and Coalescence in Sandy Mudstone with Prefabricated Cross-Flaws Under Uniaxial Compression
}

\author{
Dongxu Liang $\mathbb{D}^{1,}{ }^{1,2}$ Nong Zhang ${ }^{(D)}{ }^{1,3}$ Haoyu Rong, ${ }^{1}$ and Zhe Xiang ${ }^{1}$ \\ ${ }^{1}$ Key Laboratory of Deep Coal Resource Mining, Ministry of Education of China, School of Mines, \\ China University of Mining \&Technology, Xuzhou 221116, Jiangsu, China \\ ${ }^{2}$ College of Sciences and Engineering, University of Tasmania, Hobart 7001, TAS, Australia \\ ${ }^{3}$ Open Laboratory for Large-scale Scientific Instruments, Jiangsu Normal University, Xuzhou 221116, Jiangsu, China
}

Correspondence should be addressed to Nong Zhang; zhangnong@cumt.edu.cn

Received 24 October 2020; Revised 17 November 2020; Accepted 18 December 2020; Published 4 January 2021

Academic Editor: Pengfei Wang

Copyright (C) 2021 Dongxu Liang et al. This is an open access article distributed under the Creative Commons Attribution License, which permits unrestricted use, distribution, and reproduction in any medium, provided the original work is properly cited.

\begin{abstract}
The purpose of this paper is to study the crack initiation, propagation, and coalescence of the sandy mudstone sample with two sets of prefabricated cross-flaws under uniaxial compression. This study is different from previous studies on single or multiple parallel prefabricated flaws. The prefabricated cross-flaws are characterized by the dip of the rock bridge with the direction of the main flaw $(\beta)$ and the angle between the direction of main and minor flaws $(\gamma)$. The effects of these two parameters on crack initiation, propagation, coalescence, crack initiation stress, and coalescence stress are analyzed. Moreover, numerical simulation of the uniaxial compression experiments is performed using PFC2D with a flat-joint model, and the simulation results are in good agreement with those from the experiments. The results demonstrate that the dip angle of the rock bridge with the direction of the main flaw $(\beta)$ has strong effects on the crack initiation and coalescence stresses. The larger the angle between the direction of main and minor flaws $(\gamma)$, the greater the crack initiation and coalescence stresses. The crack initiation stress is reduced for the case with cross-flaws compared with that with non-cross-flaws. Meanwhile, the connection type of main flaws and the width of the crack coalescence zone are difficult to observe through the experiments and are discovered from the numerical simulation.
\end{abstract}

\section{Introduction}

Faults and joints in rocks affect the mechanical properties of rocks. Therefore, it is of great significance to study the initiation and propagation modes of cracks in rocks for the failure mechanism of rocks [1]. The study of the rock failure process mainly includes three aspects: experiment, theory, and numerical simulation.

In order to study the crack evolution mode during the failure of crystalline rock materials, many researchers have conducted laboratory experiments with rock materials such as resin, plexiglass, or gypsum and analyzed the initiation, propagation, and coalescence of wing cracks and secondary cracks which lead to the macroscopic failure of brittle materials [2]. These prismatic samples of rock-like materials which are usually prefabricated with one, two, or more cracks with different geometric parameters and are subjected to uniaxial compression test crack [3,4], crack coalescence categories [4-6], crack initiation criteria $[7,8]$, and crack propagation patterns in different rock-like materials [9] were studied from different perspectives, which is helpful to the identification of rock cracks and the study of failure mechanism. Three types of cracks are observed during the rock failure process [4]: tensile cracks, mixed tensile-shear cracks, and shear cracks (Figure 1). The types and forms of crack coalescence are summarized through experiments and have been classified into nine categories [10-12]. Open flaws and closed flaws had a substantial difference in terms of mechanical behaviors $[12,13]$. The digital speckle correlation method [14], scanning electron microscopy, and environmental scanning electron microscopy imaging techniques [4], as well as active seismic monitoring [15] are 


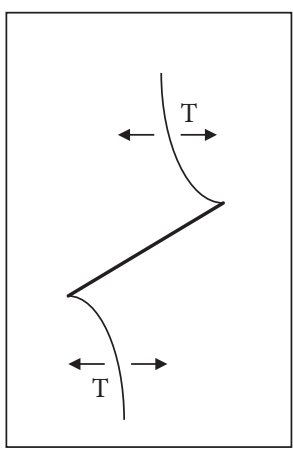

(a)

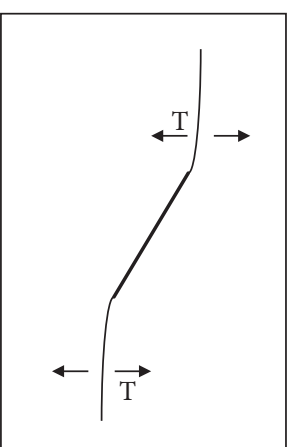

(b)

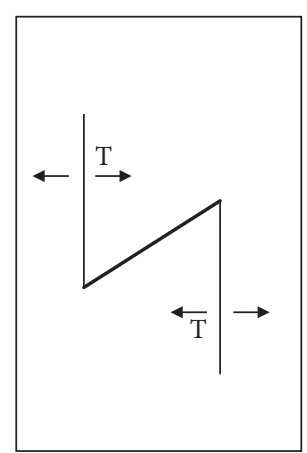

(c)

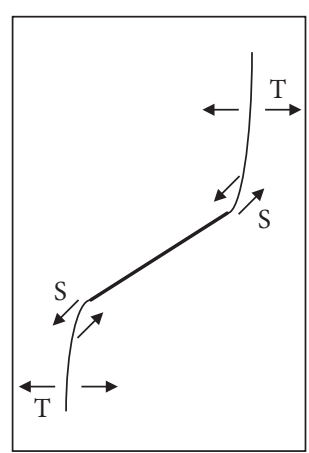

(d)

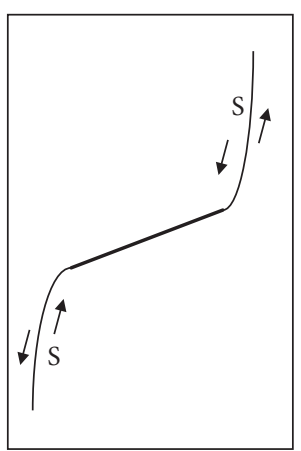

(e)

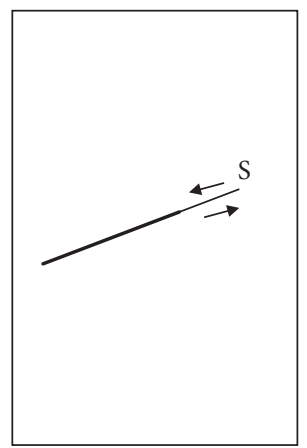

(f)

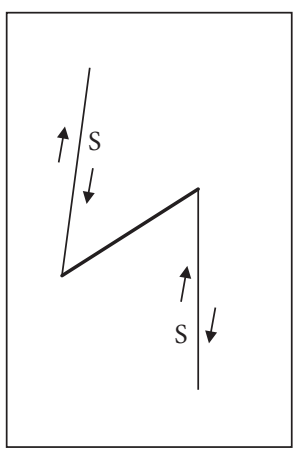

(g)

Figure 1: Various types of cracks induced by prefabricated flaws (Wong and Einstein [4]). Tand S represent tensile crack opening and shear sliding, respectively. (a) Type 1 tensile crack (tensile wing crack). (b) Type 2 tensile crack. (c) Type 3 tensile crack. (d) Mixed tensile-shear crack. (e) Type 1 shear crack. (f) Type 2 shear crack. (g) Type 3 shear crack.

applied to monitor the strain field of crack propagation. Hoek suggested that the crack propagation caused by the single crack could not explain the macrofracture in specimens [16]. Besides, compared with the effect of confining pressure (5-20 MPa), preexisting cracks have a greater impact on rock deformation, strength, and fracture coalescence [17]. In addition to the uniaxial compression test, the Brazilian split test of precracked specimens was also carried out to study crack propagation and coalescence [18-22], by focusing on the effects of inherent rock properties. Three failure mechanisms are found in the shear test of discontinuous jointed granite, in which the shear properties and failure mechanisms are also analyzed [23]. In the above research, the cracks existing in the rock mass are simplified as straight cracks or pore cracks. However, some researchers believe that elliptical defects are also common types of defects in practical engineering. They studied the ultimate failure mode of sand specimens with two prefabricated elliptical defects [24]. Experimental studies on single ellipse defects show that the extension of tensile cracks around the pores of marble specimens is mainly affected by the nucleation and propagation of local strain zones [25]. Although in many studies in the past, various experiments and complex monitoring methods have been widely used. Real-time dynamic monitoring has extremely high requirements on the size and accuracy of the sensor and the method of CT scanning while loading is too expensive, so the available experimental methods are still not enough to explore the relevant micromechanisms.
The crack propagation in brittle materials with prefabricated flaws has long been explored using theoretical methods in the last century, and especially, many theoretical models for mixed-mode I-II crack initiation have been developed. Stress-based [26-31], energy-based [32-37], and strain-based $[38,39]$ are three main theories. The modified maximum-circumferential stress criterion, proposed based on the maximum circumferential stress, takes into account the changing elastoplastic boundary of the crack tip [40]. However, since these existing failure criteria are established based on tensile loads rather than compressive loads, these criteria are only valid in the positive region (crack opening). Therefore, they cannot predict fracture behavior in the negative region (crack closure). Numerical simulation methods are widely used in the study of crack propagation in rock materials and are especially suitable for situations that cannot be completed in the laboratory. The discrete element method is the most popular and general method for simulating crack propagation and coalescence in rock materials [41]. In the particle flow model, a bonded particle model (BPM) is proposed, which uses round or spherical particles in the dense accumulation of contact points representing the rock [42]. Based on the proposed BPM model, simulation about crack propagation and coalescence for many rocks have been carried out, which achieved consistent results as those obtained in the laboratory [43-46]. Three inherent problems encountered in the application of the standard BPM model and their causes were also elaborated [47]. Simulation studies using the finite element method and 
nonlinear dynamics method show that, under different loading conditions, the mixed crack type, crack initiation sequence, and overall crack shape differ with the rock [48]. Besides, the boundary element method is proven by a study of comparing the experiment and numerical simulation of Brazilian splitting test to be efficient and easy, compared with PFC2D [19].

In summary, in experiments to study the propagation of cracks using rock-like materials with different proportions, as described above, cementation of particles in similar materials can result in a much lower ratio of compressive and tensile strength than in real rocks. In quarry simulations using the BPM model in PFC2D, the obstruction of the model itself to simulate particle locking also contributes to a lower rate of rock compression for tensile strength than natural rock materials. When the BPM model is used, (1) the ratio of unilaterally limited uniaxial compressive strength to tensile strength (UCS/TS) is unrealistically in the range of $3-7$, (2) the internal friction angle is too low than the true value, and (3) the strength envelope line is linear, i.e., the Hoek-Brown (HB) strength parameter $m_{i}$ is small. The interface in the FJM model is resistant to rotation even after disconnection, whereas it is not in the standard BPM. Consequently, the BPM cannot be used to assess the impact of the compression/tensile strength ratio on crack propagation. Besides, the previous studies discussed above have mainly focused on single faults, double parallel faults, or multiple parallel faults, while in rock mass engineering with real fault, the faults are often crossed (Figure 2). Therefore, we present here an experimental and numerical study on transversal defects closer to the real situation. The uniaxial compression tests are performed first on samples of sandy clay containing two sets of transverse faults to examine the effects of the length of the rock bridge between the transverse faults, the angle between the main fault and the loading direction, and the inclination of the bridge of rock with the main fault, and the angle between the main fault and small defects in the propagation and fusion of cracks in defective rock masses. The Flat Joint Model (FJM) in PFC2D is then applied to simulate the uniaxial compression tests of rock samples with prefabricated transverse faults and to study the effects of different compression/tensile strength ratios on the type of crack and rock failure mechanism. New conclusions are drawn to provide a reference to elucidate the failure mechanism of rock masses with transversal faults.

\section{Specimen Preparation and Apparatus}

Sandy mudstone specimens $(70 \mathrm{~mm} \times 35 \mathrm{~mm} \times 140 \mathrm{~mm})$ were first prepared. Two holes were drilled in the rock sample (i.e., the intersection of the cross-flaws) with a round drill bit of $0.1 \mathrm{~mm}$ diameter, and based on this location, the cross flaws were cut with a wire saw. Each set of cross-flaws comprised a $12 \mathrm{~mm}$-long main flaw and an $8 \mathrm{~mm}$-long minor flaw. As illustrated in Figure 3, the distance between the endpoints of the rock bridge of the two main flaws is $L_{r}=12 \mathrm{~mm}$, and the main flaw is at $45^{\circ}$ with the axial load. $\beta$ represents the angle between the directions of the main-flaw rock bridge and main flaw, namely, the dip of rock bridge,

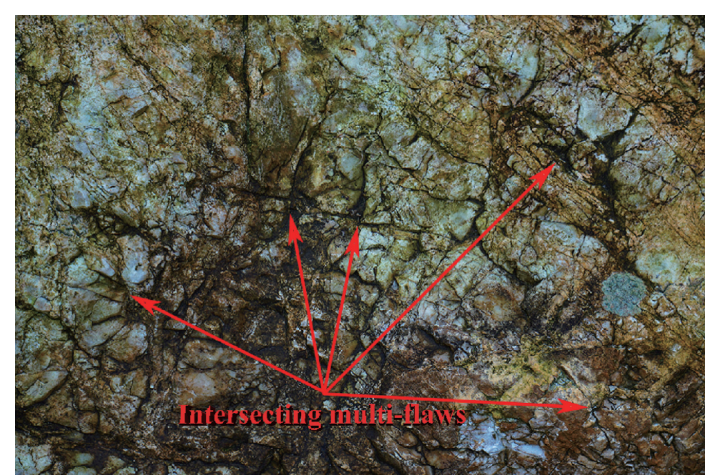

Figure 2: A rock mass containing cross-flaws.

which varies from $-60^{\circ}$ to $120^{\circ}$ at $30^{\circ}$ intervals; $\gamma$ is the angle between the directions of the main and minor flaws, i.e., $0^{\circ}$, $30^{\circ}, 75^{\circ}$, and $90^{\circ}$. The combinations of the two geometric parameters eliminated yield of 11 specimens with the prefabricated cross-flaws (Table 1). An acoustic wave detector was used to remove rocks with large differences in wave velocity to ensure that the physical and mechanical properties of the specimen were as consistent as possible. Three replicates were prepared for each specimen, and a total of 33 specimens were used for uniaxial compression test. The specimens were named as follows: $30-45$ represents the specimen with $\beta=30^{\circ}$ and $\gamma=45^{\circ}$.

To obtain the physical-mechanical properties of the sandy mudstone specimens, uniaxial compression and Brazilian splitting tests were conducted on cylindrical standard specimens $(50 \mathrm{~mm} \times 100 \mathrm{~mm})$ [49]. Young's modulus $(E)$, uniaxial compressive strength (UCS, $\sigma_{c}$ ), Poisson's ratio $(v)$, and uniaxial tensile strength (TS, $\sigma_{t}$ ) of the specimens were obtained by averaging the results of five laboratory experiments (Table 2).

The uniaxial compression tests of the sandy mudstone specimens with the prefabricated cross-flaws were carried out using the MTS-816 electro-hydraulic servo-controlled rock mechanics testing system. During each test, crack initiation, propagation, and coalescence were recorded using a high-speed recording system (Figure 4). To ensure that the rock is tested in a quasi-static condition, displacement loading was applied at a loading rate of $0.002 \mathrm{~mm} / \mathrm{s}$ [5] in the experiment, and the high-speed recording system captured 100 frames per second.

\section{Experimental Results}

This section can be divided into two sections as follows. In Section 3.1, the influence of the dip angle of the rock bridge with main flaw of prefabricated cross-flaws on the crack propagation is obtained. In Section 3.2, the effect of the angle between main and minor flaws on crack initiation and coalescence are analyzed.

3.1. Effect of the Dip Angle of Rock Bridge with Main Flaw. To analyze the effects of the dip angle $\beta$ on crack propagation and coalescence (one-to-one correspondence with pictures of each group from left to right), $\gamma=45^{\circ}$ was selected while 


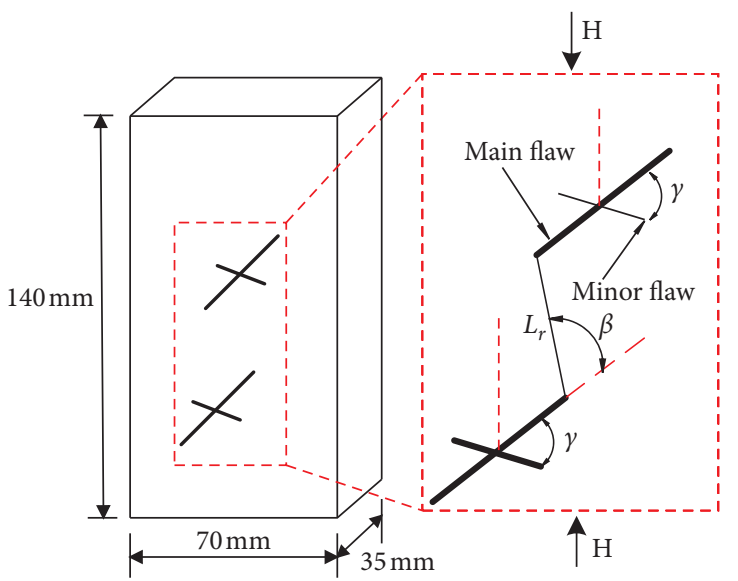

(a)

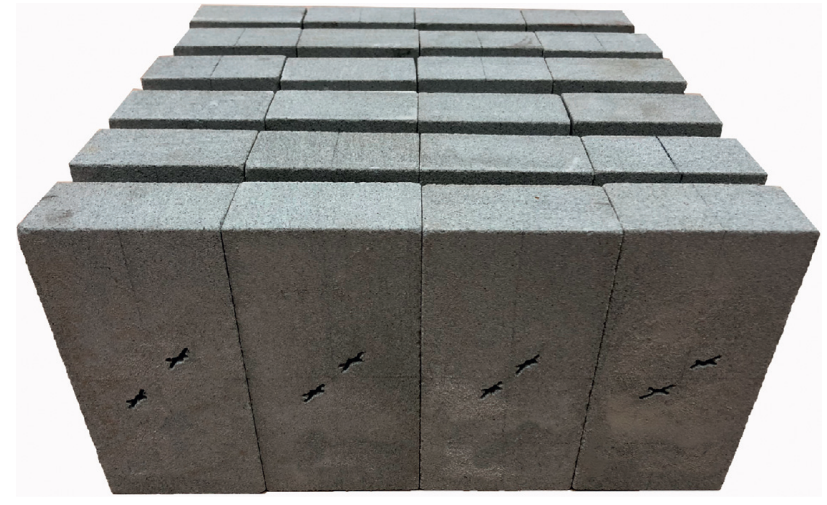

(b)

Figure 3: Specimens with cross-flaws: (a) schematic sketch of the flaw geometry in sandy mudstone specimens and (b) sandy mudstone specimens with prefabricated flaws.

TABLE 1: List of sandy mudstone specimens with prefabricated cross-flaws.

\begin{tabular}{lcc}
\hline Specimen number & $\beta\left(^{\circ}\right)$ & $\gamma\left(^{\circ}\right)$ \\
\hline$(-60)-45$ & -60 & 45 \\
$(-30)-45$ & -30 & 45 \\
$0-45$ & 0 & 45 \\
$30-45$ & 30 & 45 \\
$60-45$ & 60 & 45 \\
$90-45$ & 90 & 45 \\
$120-45$ & 120 & 45 \\
$30-0$ & 30 & 0 \\
$30-30$ & 30 & 30 \\
$30-75$ & 30 & 75 \\
$30-90$ & 30 & 90 \\
\hline
\end{tabular}

TABle 2: Physical and mechanical parameters of sandy mudstone specimens.

\begin{tabular}{lc}
\hline Properties & Sandy mudstone specimen \\
\hline Density $\left(\mathrm{g} / \mathrm{cm}^{3}\right)$ & 2.30 \\
Young's modulus $(\mathrm{GPa})$ & 4.51 \\
Uniaxial compressive strength $(\mathrm{MPa})$ & 28.12 \\
Tensile strength $(\mathrm{MPa})$ & 1.73 \\
Poisson's ratio & 0.27 \\
\hline
\end{tabular}

changing the dip angle $\beta$. The seven specimens photographed by the high-speed recording system are shown in Figure 5.

In the specimen (-60)-45, type III tensile cracks first occur at the left tip of the top main flaw as well as the right tip of the bottom main flaw (Figure 5(a)). Then, the secondary cracks are initiated at the left tip of the top main flaw. With increasing load, the secondary cracks begin to occur at the right tip of the top minor flaw as well as the left tip of the bottom minor flaw. Meanwhile, a tensile crack zone is generated in the middle of the rock bridge between minor flaws. The secondary cracks link to the tensile crack zone in

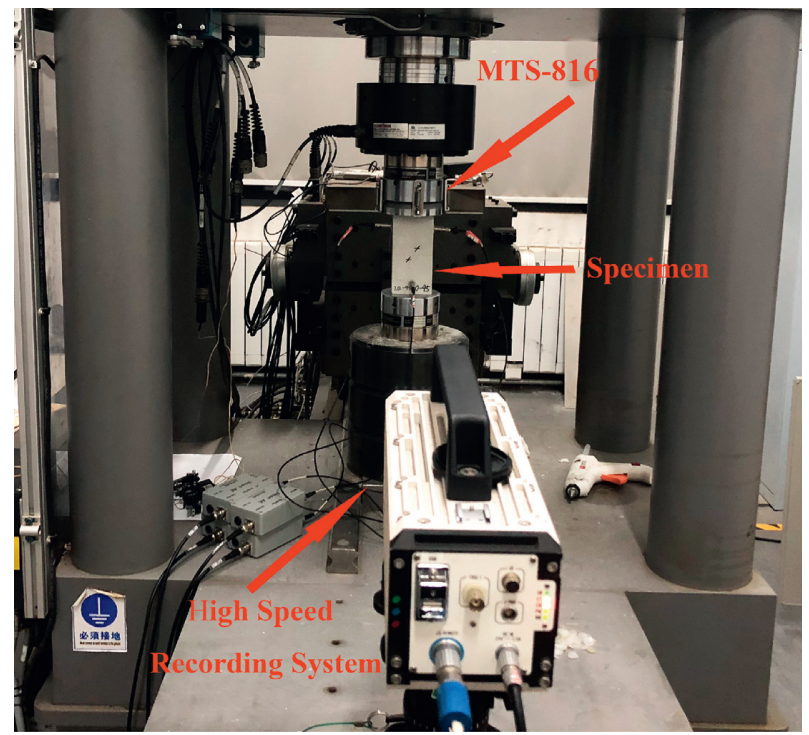

FIGURE 4: The rock mechanics testing system used for the uniaxial compression tests of the sandy mudstone specimens with the prefabricated cross-flaws.

the rock bridge between minor flaws under stress, causing crack coalescence in category VII. The type III stretch cracks initiated at the right tip of the bottom main flaw propagate and generate secondary cracks, which coalesce with the existing cracks, causing oblique shear failure.

In the specimen (-30)-45, type III tensile cracks are first, which link up the main and minor flaws (Figure 5(b)). Additionally, type I tensile cracks are initiated at the right tip of the minor flaw, whereas type III tensile cracks are generated at the left tip of the top main and minor flaws as well as the two tips of the bottom main and minor flaws. With increasing axial load, mixed tensile-shear cracks occurs, whereas the secondary crack occurs in the middle of the rock bridge between the two minor flaws, causing U-shaped 

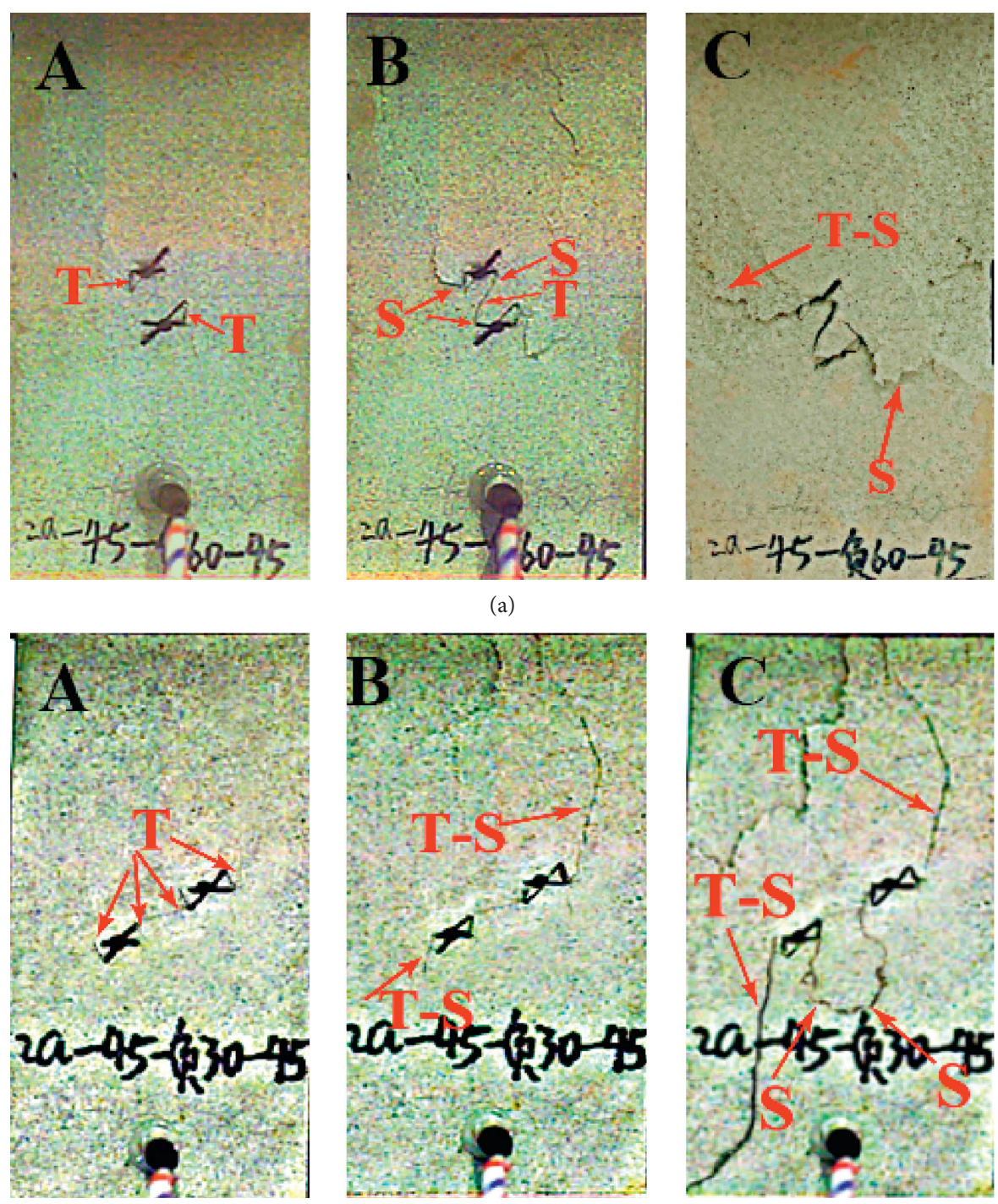

(b)
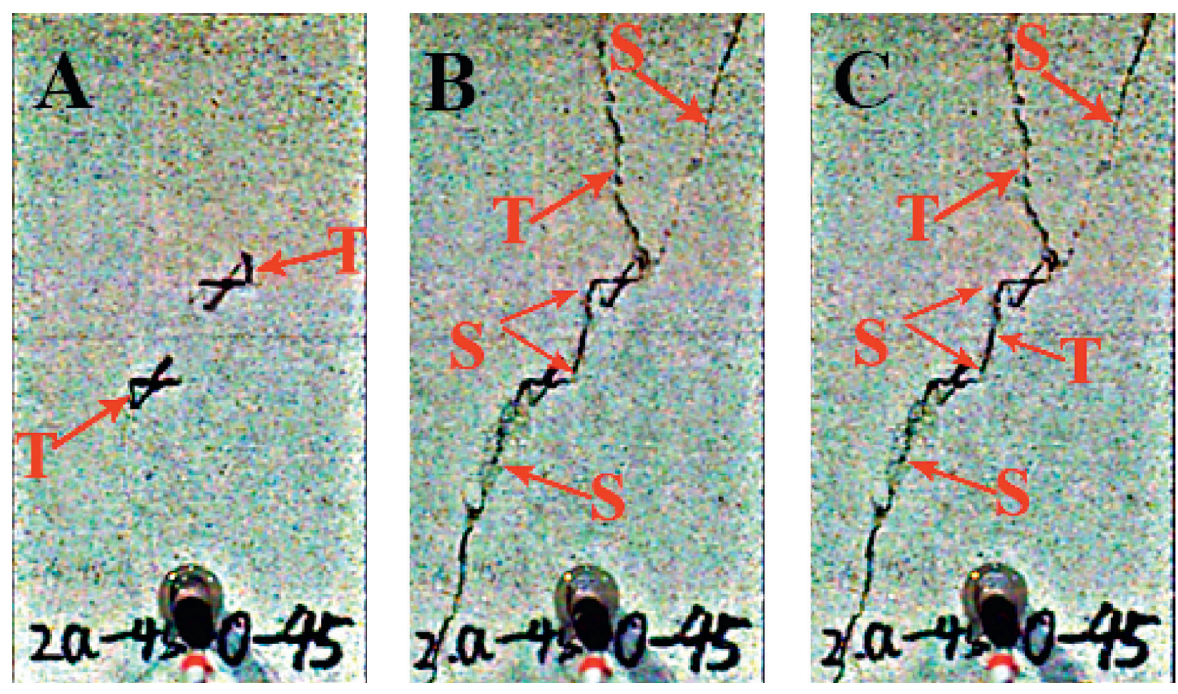

(c)

Figure 5: Continued. 

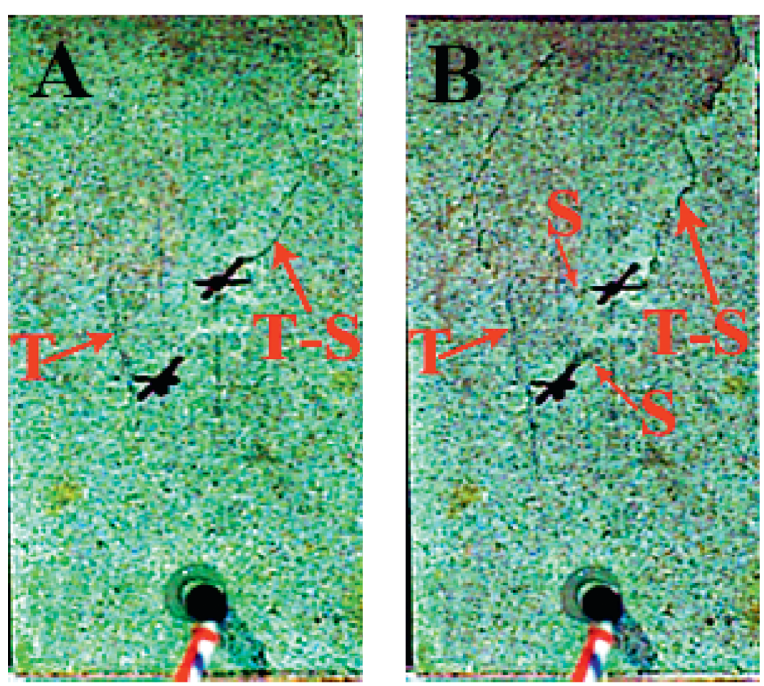

(d)
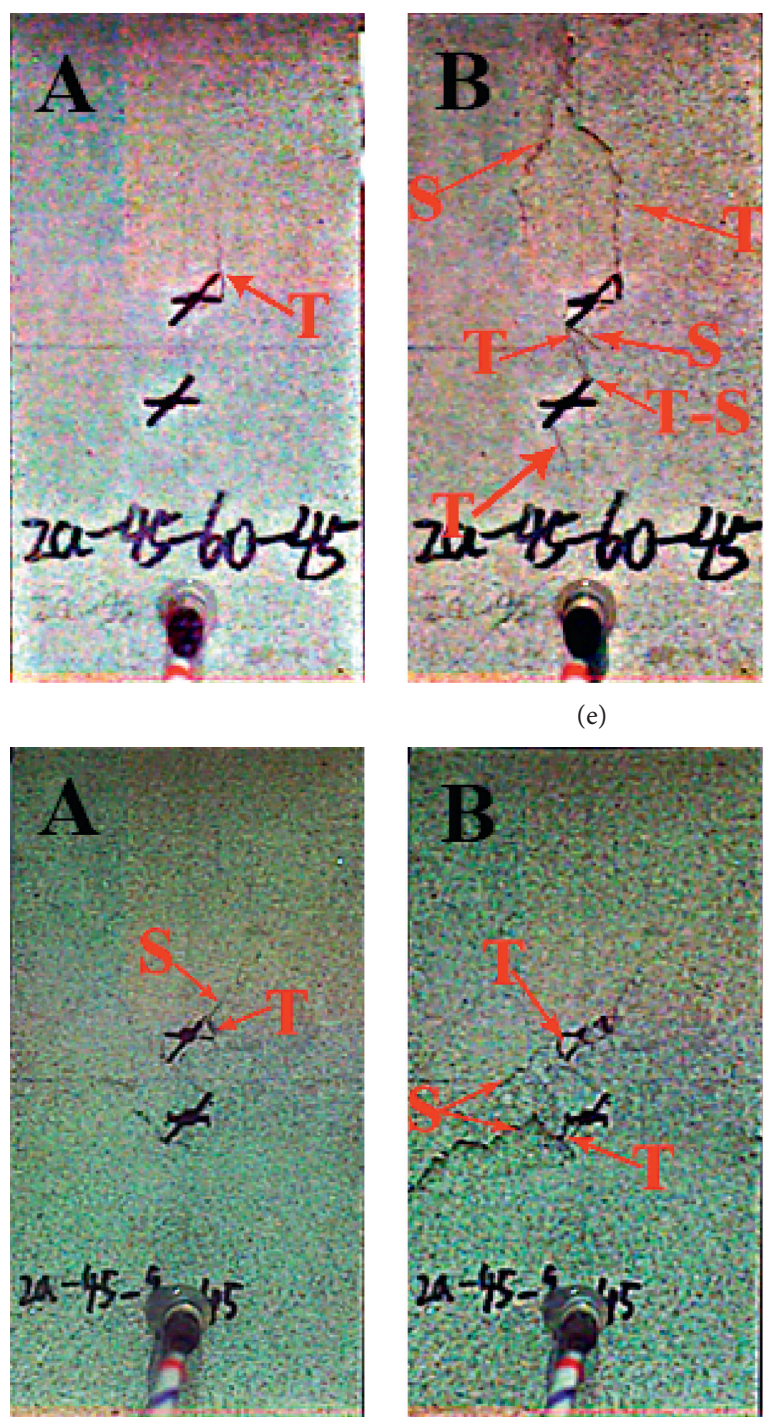

(e)

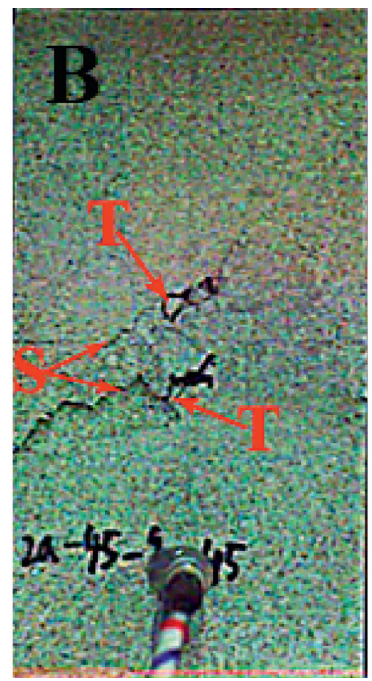

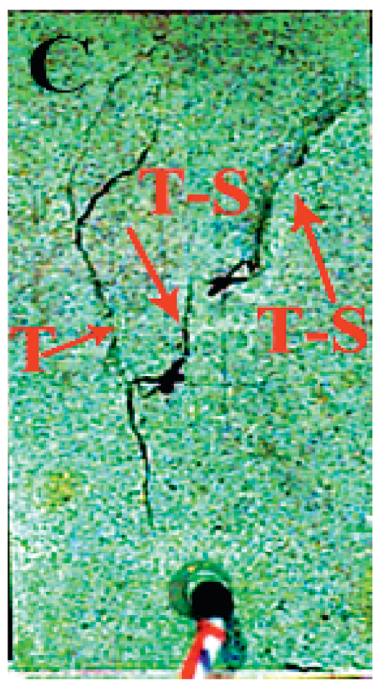
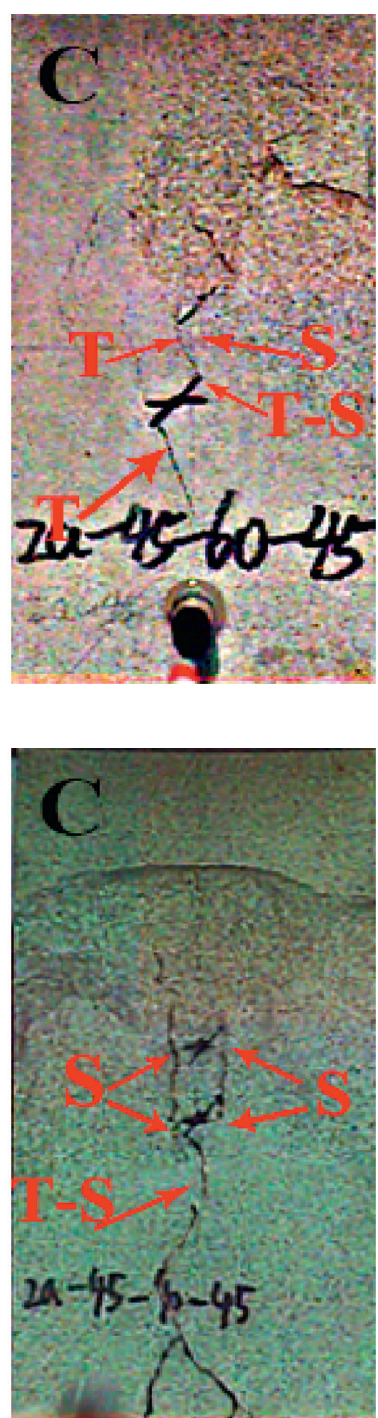

(f)

Figure 5: Continued. 

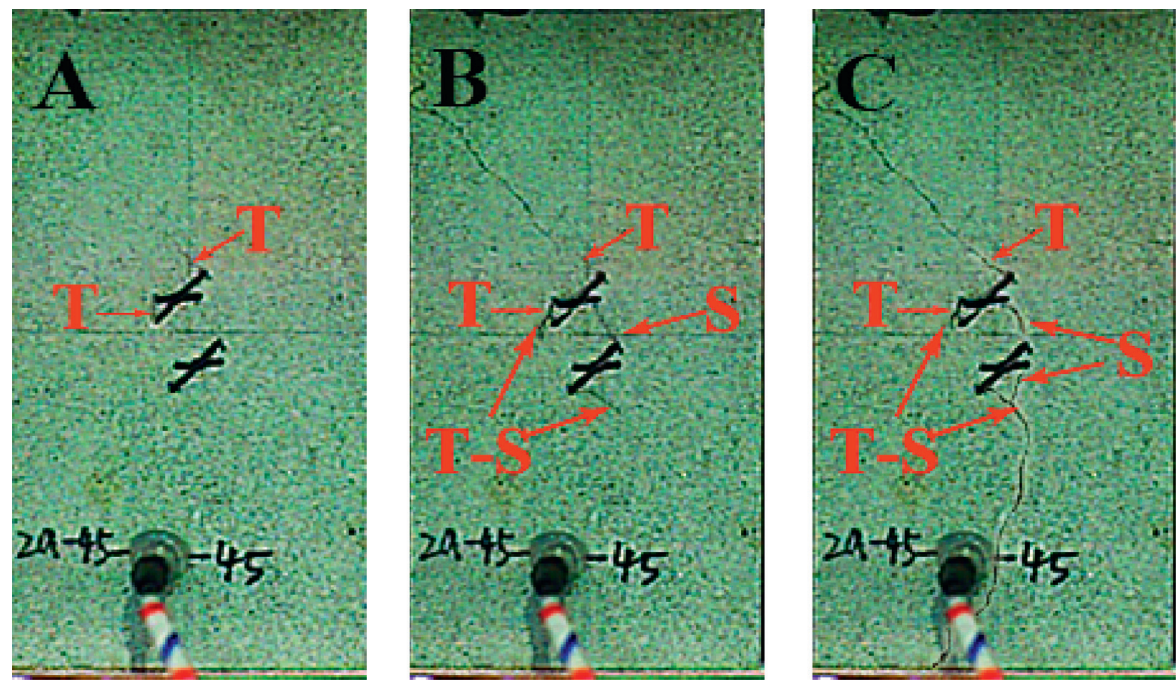

(g)

Figure 5: Crack propagation in specimens for different dips of the rock bridge with main flaw ((T) tensile crack, (S) shear crack, and (T-S) mixed tensile-shear crack). (a) $\beta=-60^{\circ}$. (b) $\beta=-30^{\circ}$. (c) $\beta=0^{\circ}$. (d) $\beta=30^{\circ}$

(e) $\beta=60^{\circ}$.

(f) $\beta=90^{\circ}$. (g) $\beta=120^{\circ}$.

coalescence cracks. Eventually, tensile failure occurs in the specimen.

In the specimen (-30)-45, type III tensile cracks are first initiated, which link to the main flaw and grow upward (Figure 5(c)). Type I shear cracks are initiated at the right tip of the top main flaw, whereas the secondary cracks occur at its left top. Meanwhile, the secondary cracks are generated at the right tip of the bottom minor flaw. With increasing load, tensile cracks are formed in the middle of the rock bridge between minor flaws, which link to the secondary cracks under stress, causing crack coalescence in category II. Meanwhile, type I shear cracks also occur at the left tip of the bottom minor flaw and then propagate, leading to Y-shaped tensile-shear failure in the rock.

In the specimen (-30)-45 (Figure 5(d)), mixed tensileshear cracks are first generated at the right tip of the top main flaw. Then, type II tensile cracks are initiated at the left tip of the bottom minor flaw and propagated upward. With increasing load, type III tensile cracks also occur at the left tip of the bottom minor flaw. A tensile crack zone appears in the middle of the rock bridge and eventually connects with the secondary cracks, leading to crack coalescence in category II. Finally, the failure mode of the specimen is a tensileshear mixed-mode failure.

In the specimen 60-45, type III tensile cracks are first initiated (Figure 5(e)). Then, the secondary cracks are generated in the middle of propagating cracks. Type III shear cracks are initiated near the lower tip of the top main flaw. Additionally, type I tensile cracks occur at the lower tip of the top main flaw, and mixed tensile-shear cracks are initiated at the upper tip of the bottom main flaw; these cracks are linked up in the rock bridge region between the two main flaws, leading to crack coalescence.

In the specimen 90-45, type III tensile cracks are first initiated (Figure 5(f)), while type II shear cracks are generated along the direction of the main flaw. Subsequently, type III tensile cracks are initiated at the left tips of the bottom and top main flaws, and the secondary cracks are initiated at the end in both cases. Crack coalescence is completed through propagation, and linking of the secondary cracks is initiated at the two tips of the top and bottom minor flaws under stress, which is classified into category $\mathrm{V}$.

In the specimen 120-45 (Figure 5(g)), type III tensile cracks are first initiated at the right and left tips of the top main and minor flaws. With increasing load, mixed tensileshear cracks occur at the left tip of the top minor flaw, whereas at the left tip of the bottom main flaw, type I tensile cracks are generated downward and type III shear secondary cracks are initiated toward the upper left. These cracks propagate and coalesce on the left of the rock bridge between main flaws. This crack coalescence is classified into category VII, and the specimen shows tensile-shear failure in an inverted 7 shape.

Comparison among Figures $5(\mathrm{a})-5(\mathrm{~g})$ reveals that, for $\beta=-60^{\circ}$, the specimens show pure shear failure; when $\beta$ is changed to $-30^{\circ}$, the failure mode shifts to tensile failure, with cracks first initiated at the tip of the main flaw. When $\beta>-30^{\circ}$, the failure mode changes to tensile-shear mixedmode failure, and the cracks begin to occur from the minor flaw. All cracks are initiated from the minor flaw for $\beta=30^{\circ}$, and the number of crack types is the largest for $\beta=90^{\circ}$.

\subsection{Effect of the Angle between Main and Minor Flaws.} To evaluate the effects of the angle $\gamma$ on crack propagation and coalescence (one-to-one correspondence with pictures of each group from left to right), $\beta=30^{\circ}$ was selected while changing $\gamma$. The four specimens for different $\gamma$ photographed by the high-speed recording system are shown in Figure 6.

In the specimen 30-0 (Figure 6(a)), the main flaw overlaps with the minor flaw; therefore, the specimen contains two prefabricated parallel flaws. Type III tensile cracks are first initiated at the right tip of the top flaw and the 

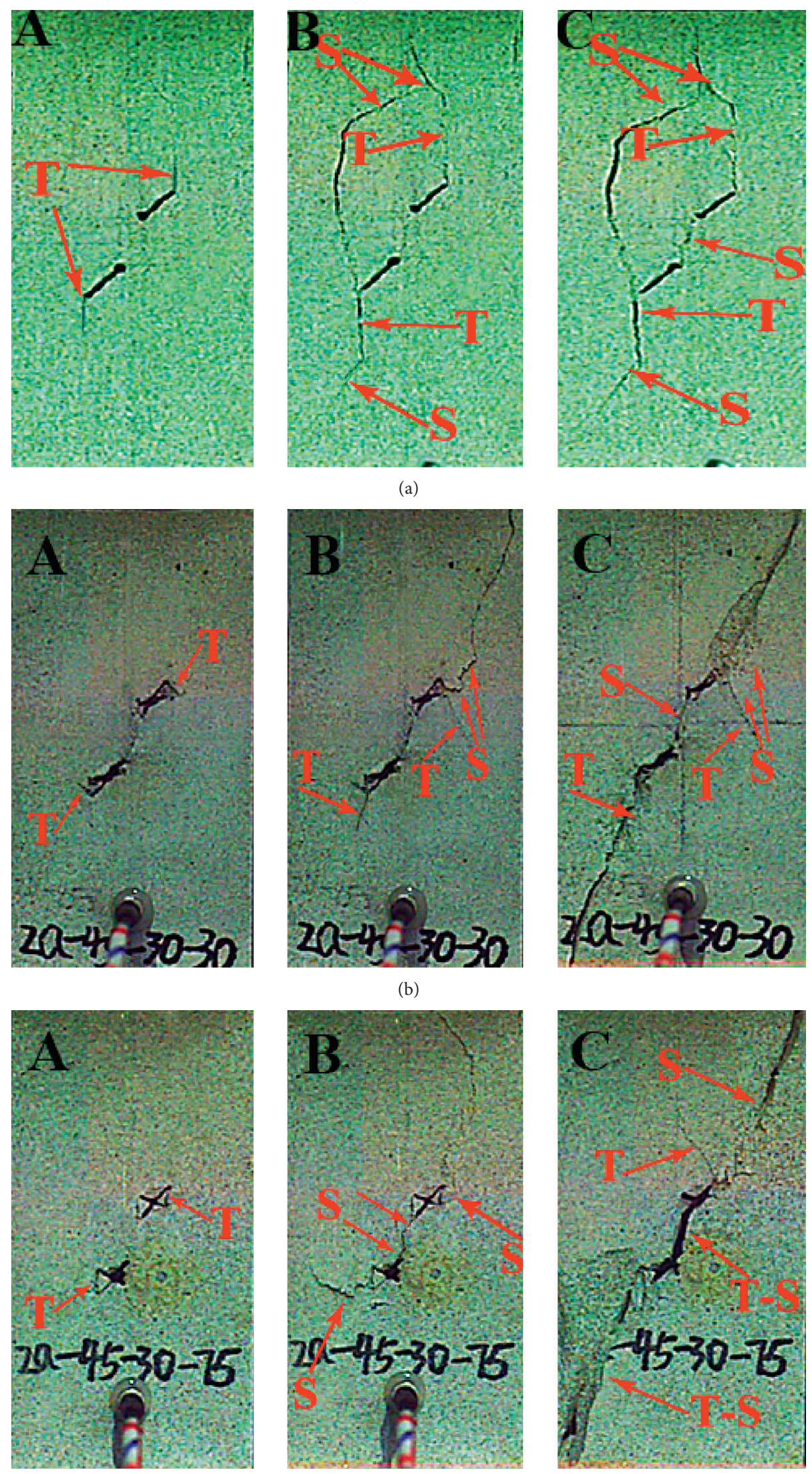

(c)

FIGURE 6: Continued. 

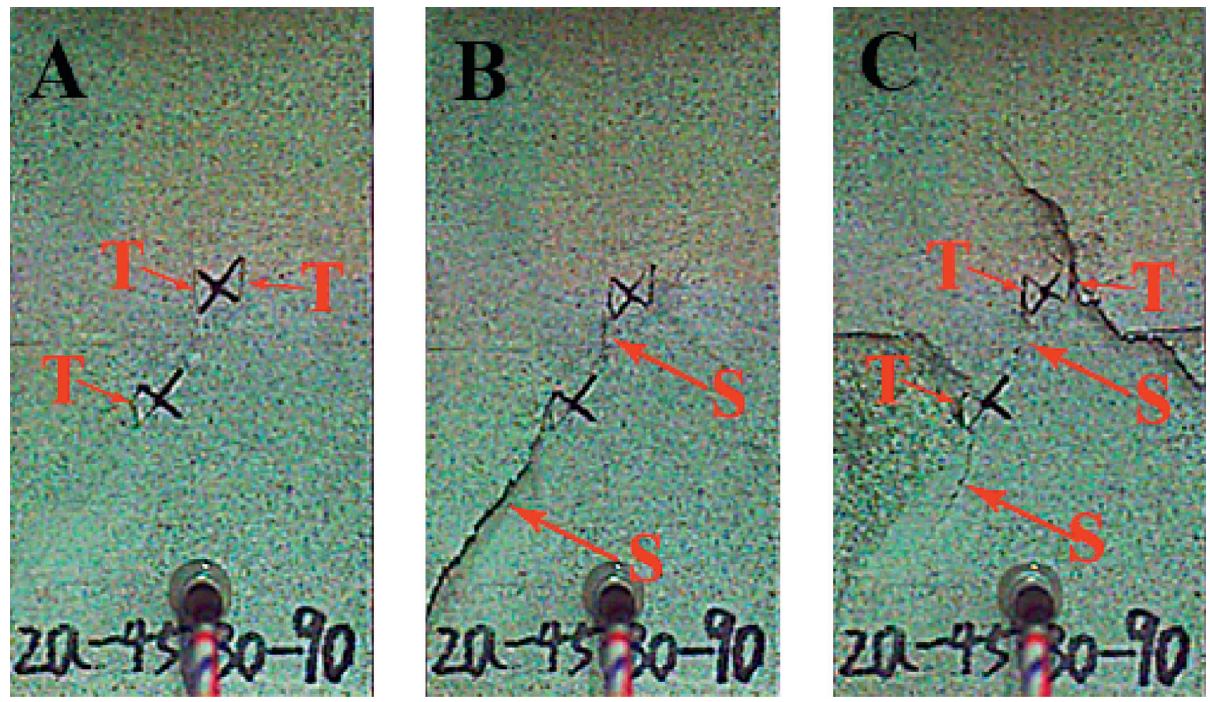

(d)

FIGURE 6: Crack propagation in specimens for different angles between main and minor flaws ((T) tensile crack, (S) shear crack, and (T-S) mixed tensile-shear crack). (a) $\gamma=0^{\circ}$. (b) $\gamma=30^{\circ}$. (c) $\gamma=75^{\circ}$. (d) $\gamma=90^{\circ}$.

left tip of the bottom flaw and then propagated in opposite directions. Additionally, the secondary cracks begin to occur near the flaw tip in the rock bridge region, leading to crack coalescence in category I. The specimen eventually shows tensile-shear failure.

In the specimen 30-30 (Figure 6(b)), type III tensile cracks are first initiated at the right tip of the top main flaw, followed by the initiation of type I shear cracks. The secondary cracks are generated at the tips of the top and bottom main flaws, which are linked up in the rock bridge region to cause crack coalescence in category I. The specimen shows oblique shear failure.

In the specimen 30-75 (Figure 6(c)), type III tensile cracks are first initiated at the right tip of the top main and minor flaws and the left tip of the bottom main and minor flaws. These cracks are subsequently linked up; type I shear cracks are generated in the middle part of the linked tensile cracks and then propagated under stress. Type I shear secondary cracks begin to occur at the tip of the main flaw close to the rock bridge, which are linked up in the middle part of the rock bridge, leading to crack coalescence in category I. The specimen finally presents oblique shear failure.

In the specimen 30-90 (Figure 6(d)), type III tensile cracks are also first initiated at the left and right tips of the top main and minor flaws. With increasing load, type II shear secondary cracks are initiated at the tip of the main flaw near the rock bridge region, which leads to crack coalescence in category I. The specimen ultimately undergoes oblique shear failure.

The comparison among Figures 6(a)-6(d) shows that the specimens undergo tensile failure for $\gamma=0^{\circ}$, whereas the failure mode changes to shear failure for $\gamma>0^{\circ}$; this indicates that cross-flaws play a role in altering the failure mode of rock masses. Irrespective of the angle $\gamma$, the crack coalescence pattern of rocks always belongs to category I; this suggests that $\gamma$ has no effect on the category of crack coalescence.

\section{Numerical Simulation}

4.1. FJM Model. The flat-joint contact and corresponding flat-jointed material are illustrated in Figure 7. Flat-joint contact simulates the interface behavior between two theoretical surfaces, and each surface is rigidly connected to an entity. A flat-joint contact material includes the entity (ball, cluster of particles, or wall) connected by the flat-joint contact so that the effective surface of each entity is defined by the notional surfaces of its various parts. These surfaces at each flat-joint contact interact with the notional surfaces of the contact entities. The notional surface is referred to as the facet, which is a line in two dimensions and a disc in three dimensions. The FJM model can be installed at the ball-ball and ball-facet contact. We regard the ball of flat-jointed material as a planar particle, each of which is depicted as a disc in two dimensions and a sphere with skirted faces in three dimensions. Further details about the FJM model concept can be found in the literature [50]. When the FJM model is installed at the point of ball-ball contact, faced grains are generated. There is an interface between each set of adjacent faces, which is discretized into elements. The interface discretization is controlled by the number of equallength elements in the radial direction. Each of the elements is either bonded or unbonded. The fracture of each bonded element would cause a partial damage to the interface, and each fracture event represents a crack. If the relative displacement at the flat-joint contact is greater than the diameter of the flat joint, the adjacent faces can be removed (because the contact may be deleted), making the relevant ball partially circular in two dimensions and spherical in three dimensions. If these balls are recontacted, their behavior would contact (if the linear contact model is assigned 


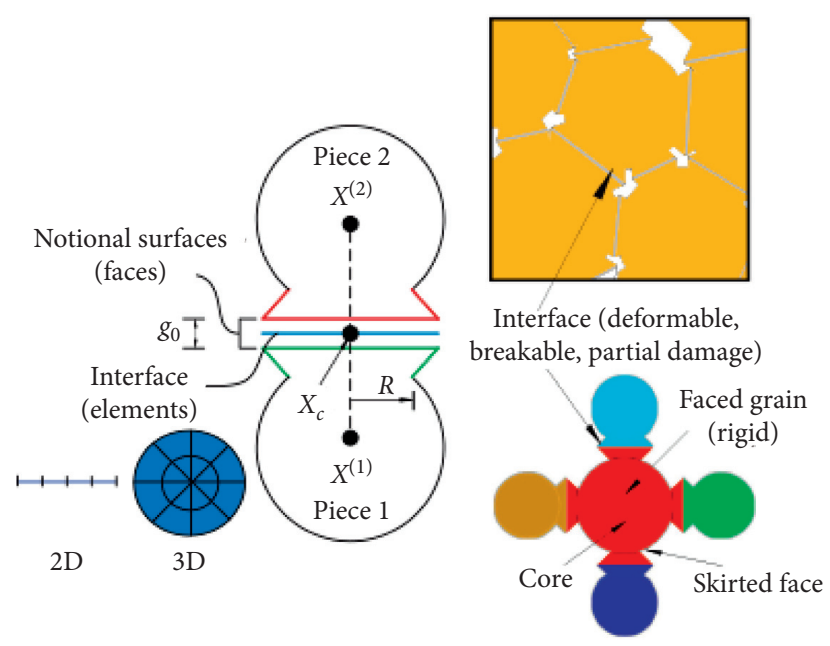

FIGURE 7: Flat-joint contact (left) and flat-jointed material (right).

to the new contact) between surfaces (disc in two dimensions and sphere in three dimensions).

The main microparameters characterizing the material constructed by the FJM model are provided in Table 3.

According to the size of sandy mudstone specimens $(35 \mathrm{~mm} \times 70 \mathrm{~mm} \times 140 \mathrm{~mm}$ ) used in the experiment (Section 2 ), rectangular cuboid model specimens containing two sets of cross-flaws were generated in the FJM model (Figure 8), with $\beta$ and $\gamma$ being changed as in the experiments. The particle radius distribution $\left(R_{\min }=0.21 \mathrm{~mm}\right.$ and $R_{\text {min }}=0.35 \mathrm{~mm}$ ) was selected according to the instructions of Itasca Company and previous studies [42, 45, 51].

4.2. Calibration of Microparameters. When applying the FJM model for numerical simulation, the microparameters need to be determined by parameter calibration. The trial and error method is most commonly used in calibrating the microparameters of the PFC2D model for rocks, that is, to continuously adjust the microparameters so that the numerical results are matched with the macromechanical properties of rocks. Here, we used Young's modulus $(E)$, Poisson's ratio $(\nu)$, uniaxial compressive strength $\left(\sigma_{c}\right)$, tensile strength $\left(\sigma_{t}\right)$, internal friction coefficient $(\tan \phi)$, and cohesion strength $(C)$ as the calibration criteria, which were obtained by uniaxial and biaxial compression tests and Brazilian splitting tests on sandy mudstone specimens.

The calibration results of the microparameters are provided in Table 3. The stress-strain curves from the uniaxial compression test are shown in Figure 9. A1-A5 are the stress-strain curves of five sandy mudstone specimens obtained by physical experiments, whereas the red line of the FJM is the stress-strain curve obtained by FJM simulation using the microparameters provided in Table 3. Clearly, the FJM model has captured most of the behaviors of sandy mudstone in physical experiments. Table 4 compares the macroparameters obtained by physical experiments and numerical simulation. The results of particle flow simulation are in good agreement with these of the physical experiments, which has verified the capability of the FJM for simulating sandy mudstone materials.

4.3. Simulation Results. Numerical simulations were conducted to model the experiments with $\beta=-60^{\circ}, 0^{\circ}$, and $90^{\circ}$ and $\gamma=0^{\circ}, 30^{\circ}$, and $75^{\circ}$ reported in Section 3 .

4.3.1. Simulation About $\beta$. Figure 10 shows the FJM model for $\beta=-60^{\circ}, 0^{\circ}$, and $90^{\circ}$ and associated photographs for crack initiation, propagation, coalescence processes, and fracture in experiment.

By comparing Figures 10(a)-10(c), we find that when $\beta=0^{\circ}$, the final failure of rocks generally shows a fracture in the connection direction of the two main flaws. However, when $\beta=-60^{\circ}$ and $90^{\circ}$, there is a near-horizontal fracture. These results are consistent with the experimental data. Additionally, for $\beta=90^{\circ}$, the types of cracks generated are most complicated, while the patterns of crack coalescence are diverse and the total number of cracks is also high. This indicates that crack propagation and coalescence in rocks are greatly affected by the dip of rock bridge, whereas the positional relationship of flaw distribution plays a considerable role in rock failure.

4.3.2. Simulation about $\gamma$. Figure 11 presents the FJM model for $\gamma=0^{\circ}, 30^{\circ}$, and $75^{\circ}$ and associated photographs for crack initiation, propagation, coalescence processes, and fracture in experiment.

As shown in Figure 11(a), when $\gamma=0^{\circ}$, the crack initiation force, peak strength, and crack coalescence force of specimens reach the maximum for all simulated specimens. This is because compared with non-cross-flaws, the presence of cross-flaws would further reduce the integrity of rock masses, resulting in a decline in their mechanical properties. In the experiments, only crack coalescence is observed in the middle of rock bridge, but the width of the crack coalescence zone cannot be observed. By contrast, the width of the crack coalescence zone is clearly seen in the simulation. When $\gamma=$ $30^{\circ}$ and $75^{\circ}$ (Figures 11(b)-11(c)), the most bond fractures occur in the middle of rock bridge, which form the widest fracture zone. The corresponding rock fracture failure is more severe.

\section{Discussion}

To study the effects of $\beta$ and $\gamma$ on crack initiation and coalescence stresses in rocks, we analyzed the experimental data and defined crack initiation and coalescence stresses as the stresses for new crack initiation and crack coalescence, respectively, as observed on the stress-strain curve (Lee and Jeon [9]).

5.1. Dip of Rock Bridge with Main Flaw. In the experiments on the specimens with different joint persistency, the stress measured by the testing system shows a slight drop and then continues to rise during crack initiation and coalescence (Figure 12). Points A, B, C, D, E, F, and G indicate the first 
TABLE 3: Microparameters of the flat-joint model.

\begin{tabular}{lcc}
\hline Microparameter & Assigned value & Physical meaning \\
\hline$R_{\min }(\mathrm{mm})$ & 0.21 & Minimum radius of particles \\
$R_{\max } / R_{\min }$ & 1.66 & Ratio of maximum radius to minimum radius of particles \\
$g_{\text {ratio }}$ & 0.3 & Installation gap ratio \\
$\Phi_{B}$ & 0.9 & The proportion of the bonding particles \\
$\Phi_{S}$ & 0.1 & The proportion of slit particles \\
$N_{r}$ & 3 & Number of elements in radial direction \\
$E_{c}=\bar{E}_{c}(\mathrm{GPa})$ & 4.80 & Effective modulus of both the particle and bond \\
$k_{n} / k_{s}=\bar{k}_{n} / \bar{k}_{s}$ & 2.40 & Normal-to-shear stiffness ratio of both the particle and bond \\
$\sigma_{b}(\mathrm{MPa})$ & 3.75 & Tensile strength \\
$c_{b}(\mathrm{MPa})$ & 21.5 & Cohesion strength \\
$\Phi_{b}\left({ }^{\circ}\right)$ & 16 & Friction angle \\
\hline
\end{tabular}

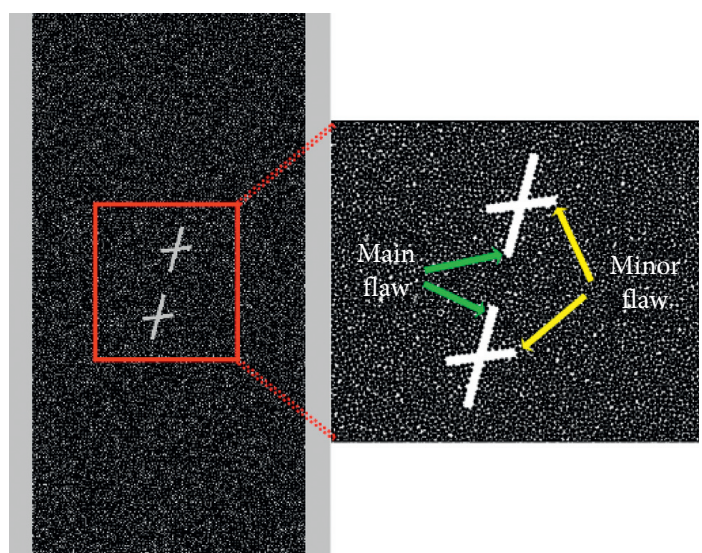

FIGURE 8: A FJM particle model of the same size as the experimental specimens.

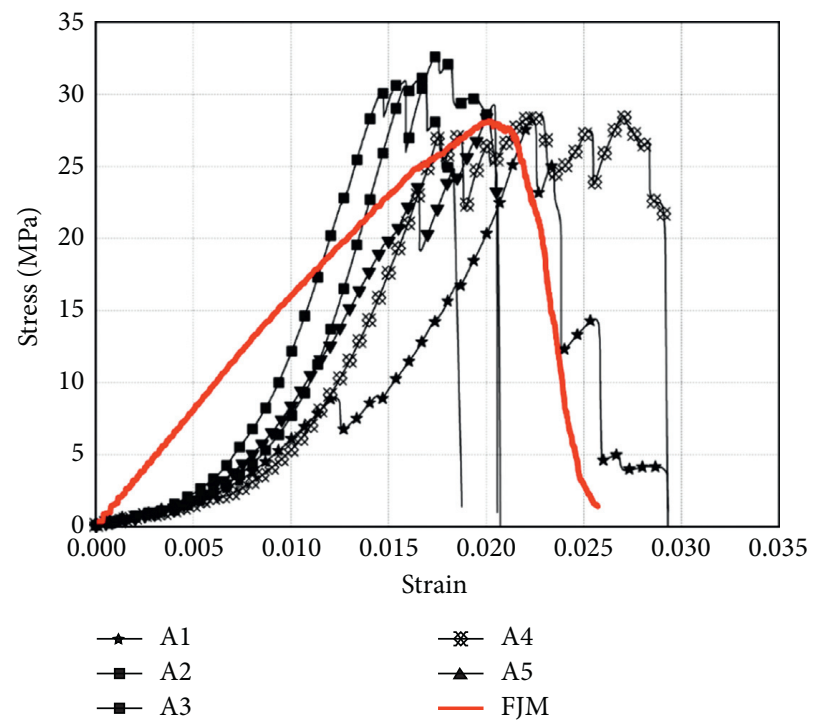

FIgURE 9: Comparison of stress-strain curves obtained by the uniaxial compression test and FJM model.

stress drop on the stress-strain curve obtained in the uniaxial compression tests of rock specimens with $\beta=-60^{\circ},-30^{\circ}, 0^{\circ}$, $30^{\circ}, 60^{\circ}, 90^{\circ}$, and $120^{\circ}$, respectively, which are the crack initiation stresses. Points $\mathrm{H}, \mathrm{I}, \mathrm{J}, \mathrm{K}, \mathrm{L}, \mathrm{M}$, and $\mathrm{N}$ indicate the corresponding second stress drop on the stress-strain curve, which are crack coalescence stresses. Because the specimens 
TABLE 4: Comparison of rock physical-mechanical parameters obtained by physical experiments and FJM simulation.

\begin{tabular}{lccc}
\hline Properties & Physical experiments & Numerical simulation & Difference $(\%)$ \\
\hline Young's modulus $(\mathrm{GPa})$ & 4.51 & 4.47 & -0.89 \\
Uniaxial compressive strength $(\mathrm{MPa})$ & 28.12 & 28.00 & -0.43 \\
Tensile strength $(\mathrm{MPa})$ & 1.73 & 1.79 & 3.35 \\
Poisson's ratio & 0.27 & 0.26 & -3.85 \\
\hline
\end{tabular}
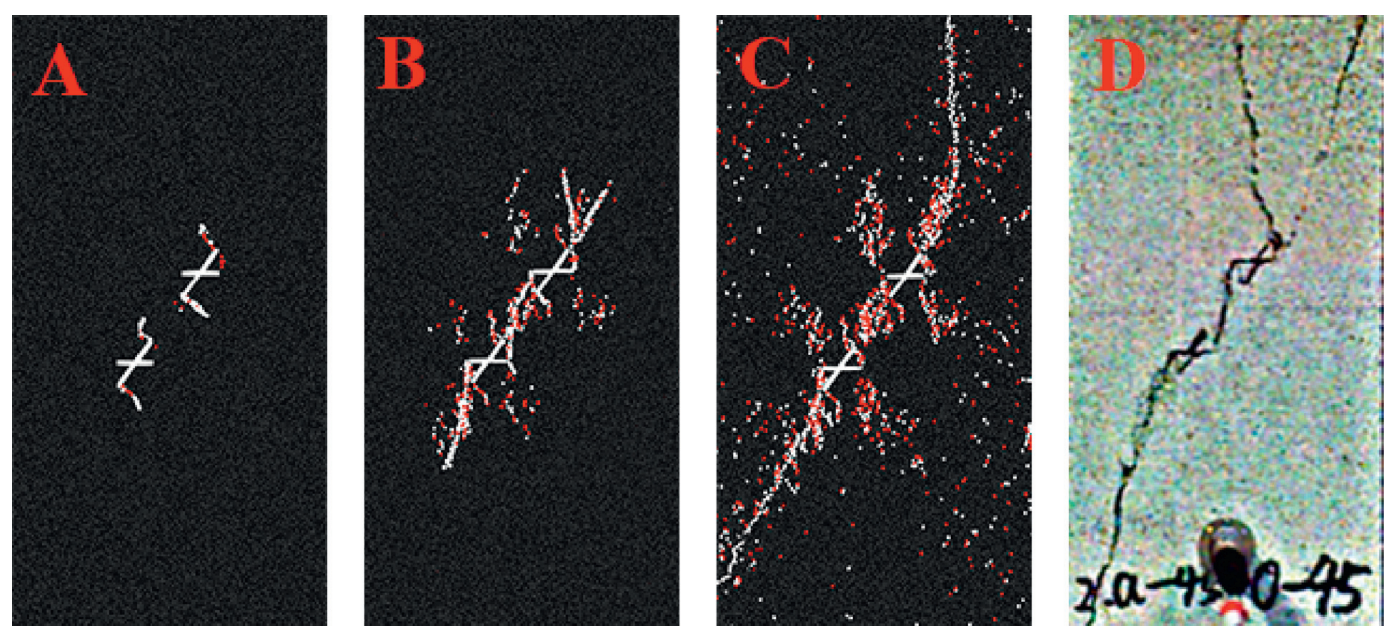

(a)
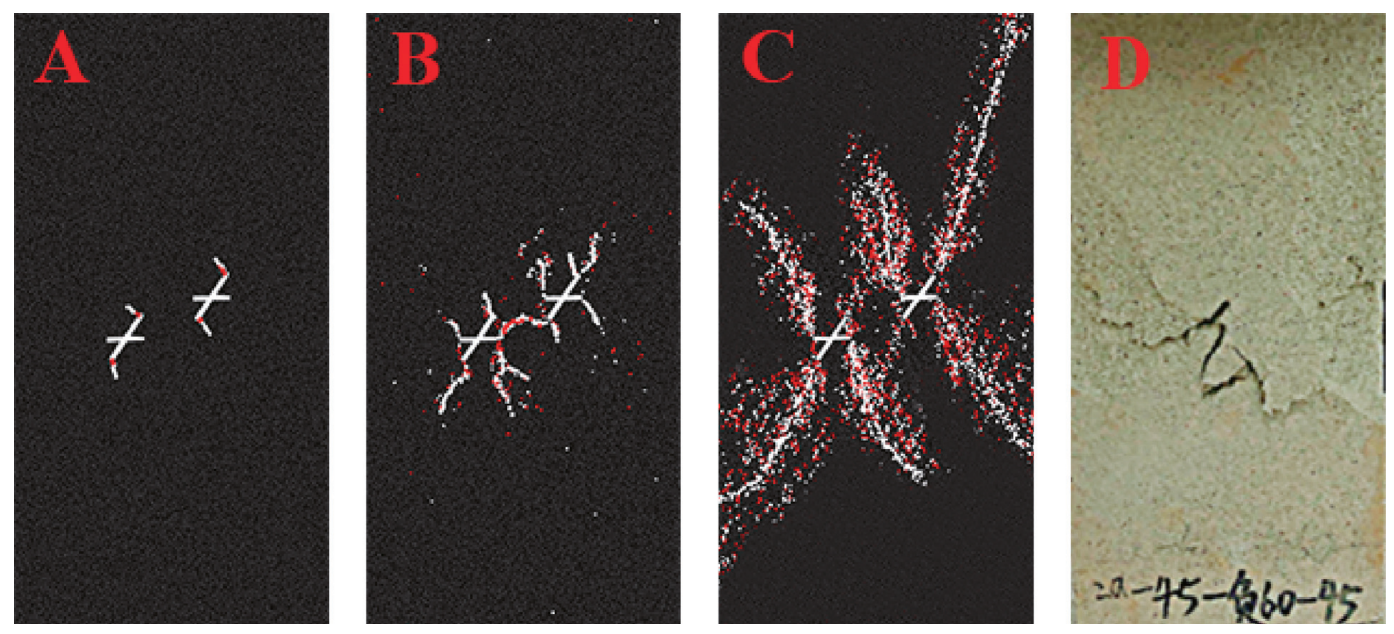

(b)
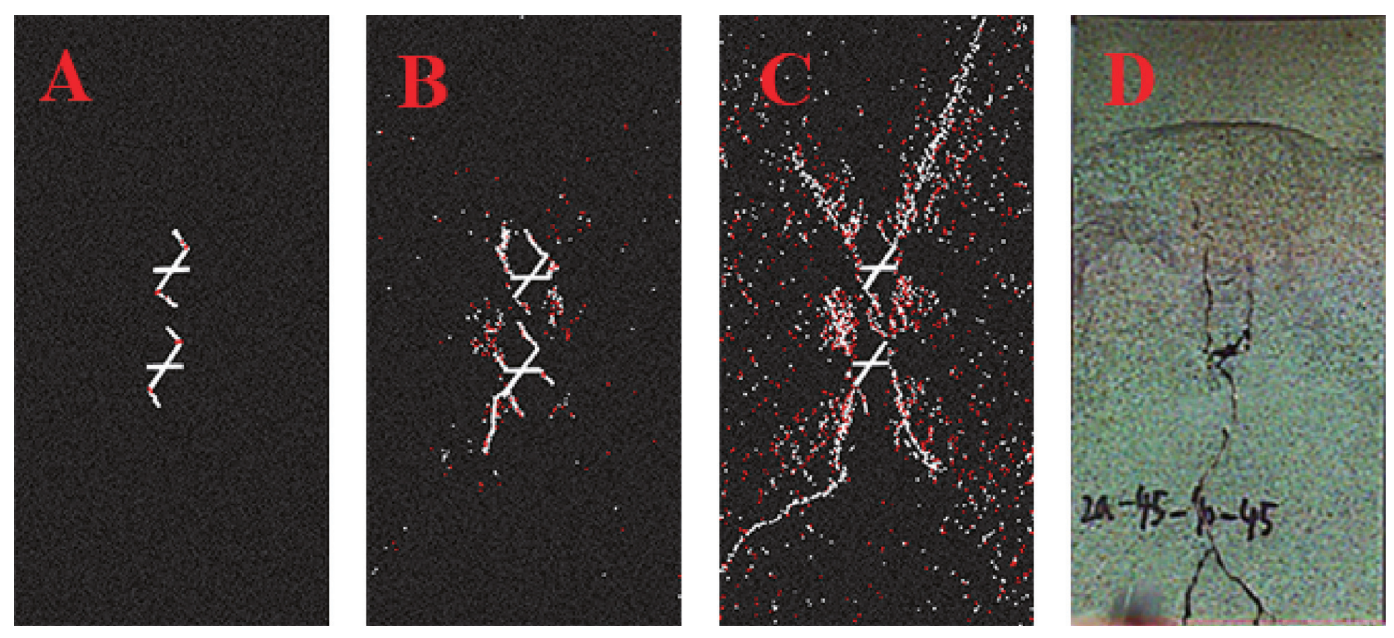

(c)

FIGURE 10: Figures of the crack propagation process in the FJM model (red and white colors indicate shear and tensile cracks, respectively) and experiments for $\beta$. (a) $\beta=-60^{\circ}$. (b) $\beta=0^{\circ}$. (c) $\beta=90^{\circ}$. 

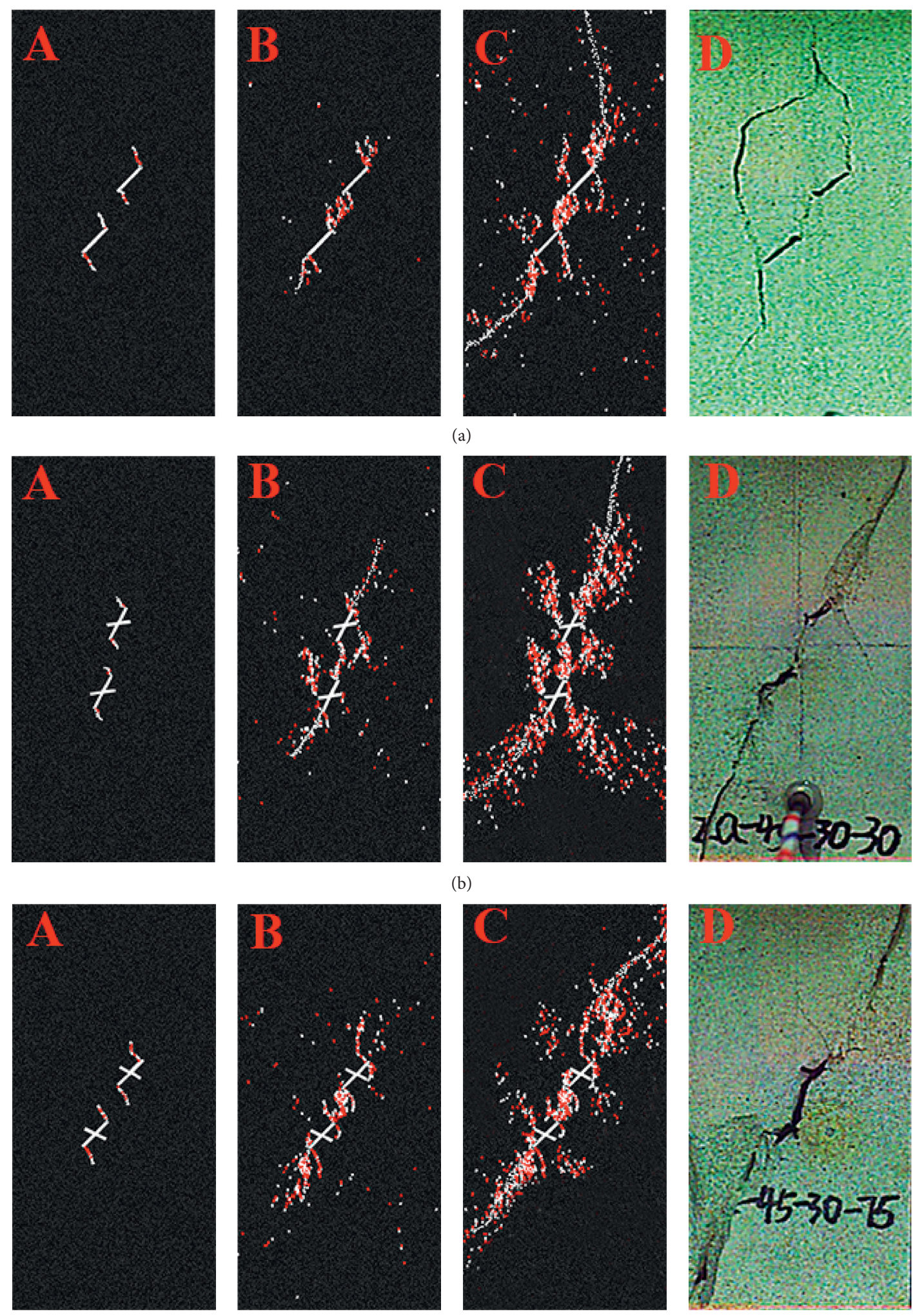

(b)
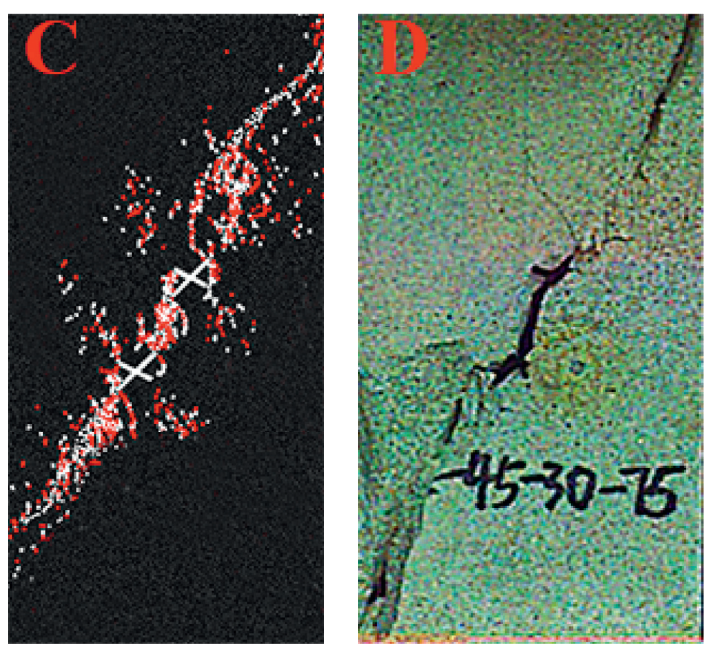

(c)

FIGURE 11: Figures of the crack propagation process in the FJM model (red and white colors indicate shear and tensile cracks, respectively) and experiments for $\gamma$. (a) $\gamma=0^{\circ}$. (b) $\gamma=30^{\circ}$. (c) $\gamma=75^{\circ}$. 


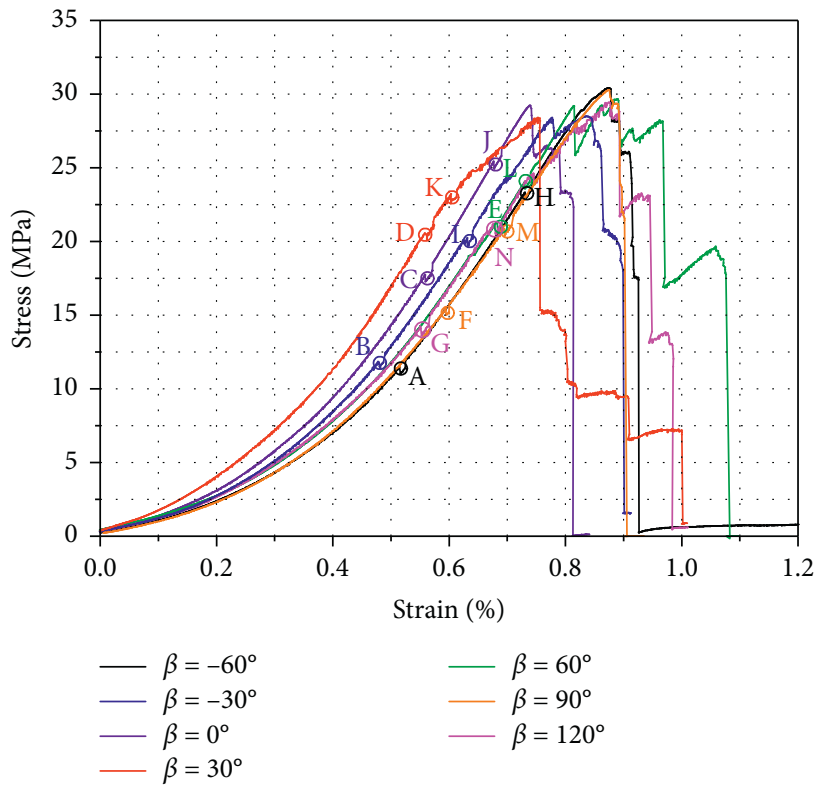

FiguRE 12: The stress-strain curve of sandy mudstone specimens for different dips of the rock bridge with main flaw $(\beta)$.

are real sandy mudstones rather than the rock made of rocklike materials, the strength of the specimens is not exactly identical due to heterogeneities. Thus, it makes little sense to simply compare the numerical values of the initiation and coalescence stresses. To reflect the effects of joint persistency on crack initiation and coalescence stresses in the rocks, the ratio $[42,45,51-55]\left(\sigma_{\mathrm{ci}} / \sigma_{c}\right)$ was used to indicate the level of the crack initiation stress relative to the peak stress and the $\left(\sigma_{c c} / \sigma_{c}\right)$ ratio to indicate the level of the crack coalescence stress relative to the peak stress, in which $\sigma_{\mathrm{ci}}$ is the crack initiation stress, $\sigma_{c c}$ is the crack coalescence stress, and $\sigma_{c}$ is the peak stress in the rock under axial compression. Based on the relationship of stresses at the points A-F and their respective peak stresses (Figure 12), the $\left(\sigma_{\mathrm{ci}} / \sigma_{c}\right)$ and $\left(\sigma_{\mathrm{cc}} / \sigma_{c}\right)$ ratios with three different $\beta$ are obtained (Table 5). The curves of $\beta$ versus $\left(\sigma_{\mathrm{ci}} / \sigma_{c}\right)$ and $\left(\sigma_{\mathrm{cc}} / \sigma_{c}\right)$ are shown in Figure 13.

The $\left(\sigma_{\mathrm{ci}} / \sigma_{c}\right)$ and $\left(\sigma_{\mathrm{cc}} / \sigma_{c}\right)$ ratios obtained at different $\beta$ are listed in Table 5. The $\left(\sigma_{\mathrm{ci}} / \sigma_{c}\right)$ ratio varies between 0.33 and 0.73 , indicating the large effect of $\beta$ on crack initiation force. The $\left(\sigma_{c c} / \sigma_{c}\right)$ ratio varies from 0.47 to 0.86 . The curves of $\beta$ versus $\left(\sigma_{\mathrm{ci}} / \sigma_{c}\right)$ and $\left(\sigma_{\mathrm{cc}} / \sigma_{c}\right)$ are shown in Figure 13 .

Both the $\left(\sigma_{\mathrm{ci}} / \sigma_{\mathrm{c}}\right)$ and $\left(\sigma_{\mathrm{cc}} / \sigma_{c}\right)$ ratios increase first and then decrease with the increasing angle $\beta$. Our results indicate that the angle $\beta$ controls the left-right positional relationship between the two sets of cross-flaws. This means the relative position of these cross-flaws has strong effects on the timing of crack initiation and coalescence. When $\beta$ varies from $-60^{\circ}$ to $30^{\circ}$, both the $\left(\sigma_{\mathrm{ci}} / \sigma_{c}\right)$ and $\left(\sigma_{c c} / \sigma_{c}\right)$ ratios increase and their maximum reached at $\beta=30^{\circ}$. When $\beta>30^{\circ}$, both $\left(\sigma_{\mathrm{ci}} / \sigma_{c}\right)$ and $\left(\sigma_{\mathrm{cc}} / \sigma_{c}\right)$ become decreasing.

5.2. The Angle between Main and Minor Flaws. The stressstrain curves for different $\gamma$ are analyzed following the method mentioned in Section 3.2 In Figure 14, A-E
TABLE 5: The crack initiation and coalescence stresses $\left(\left(\sigma_{\mathrm{ci}} / \sigma_{c}\right)\right.$ and $\left.\left(\sigma_{\mathrm{cc}} / \sigma_{c}\right)\right)$ for different dips of the rock bridge with main flaw $(\gamma)$.

\begin{tabular}{lccccc}
\hline$\beta\left(^{\circ}\right)$ & $\sigma_{\mathrm{ci}}(\mathrm{MPa})$ & $\sigma_{\mathrm{cc}}(\mathrm{MPa})$ & $\sigma_{c}(\mathrm{MPa})$ & $\left(\sigma_{\mathrm{ci}} / \sigma_{c}\right)$ & $\left(\sigma_{\mathrm{cc}} / \sigma_{c}\right)$ \\
\hline-60 & 11.51 & 23.37 & 34.88 & 0.33 & 0.67 \\
-30 & 13.66 & 23.10 & 32.53 & 0.42 & 0.71 \\
0 & 17.78 & 25.49 & 33.54 & 0.53 & 0.76 \\
30 & 23.77 & 26.37 & 32.56 & 0.73 & 0.81 \\
60 & 21.18 & 24.06 & 33.49 & 0.63 & 0.72 \\
\hline 90 & 17.66 & 23.89 & 34.62 & 0.51 & 0.69 \\
\hline 120 & 14.15 & 21.57 & 33.70 & 0.42 & 0.64 \\
\hline
\end{tabular}

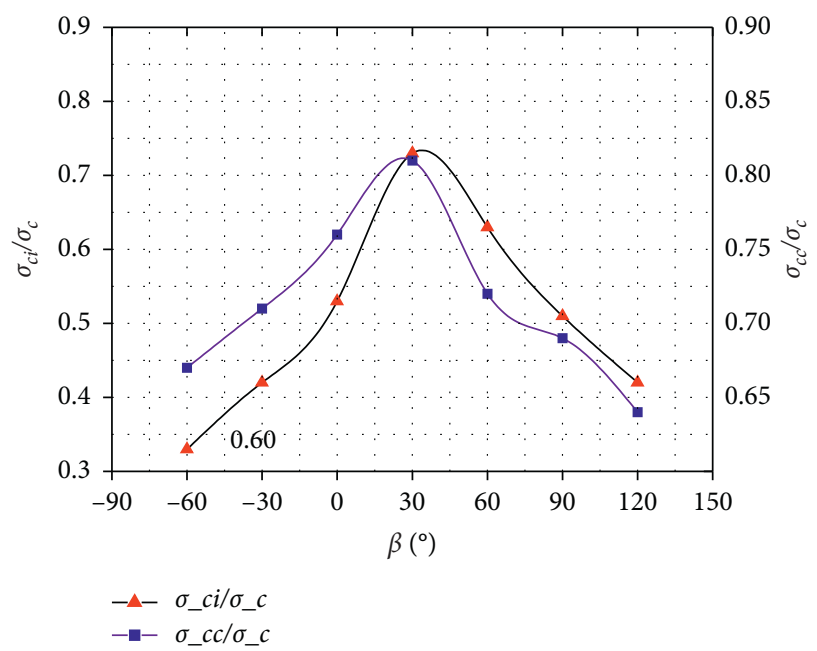

FIgURE 13: The dip of the rock bridge with main flaw $(\beta)$ versus the crack initiation and coalescence stresses $\left(\left(\sigma_{\mathrm{ci}} / \sigma_{\mathrm{c}}\right)\right.$ and $\left.\left(\sigma_{\mathrm{cc}} / \sigma_{c}\right)\right)$.

represent the crack initiation stresses of specimens for $\gamma=0^{\circ}, 30^{\circ}, 45^{\circ}, 75^{\circ}$, and $90^{\circ}$; H-L represent the corresponding crack coalescence stresses. The $\left(\sigma_{\text {ci }} / \sigma_{c}\right)$ and 


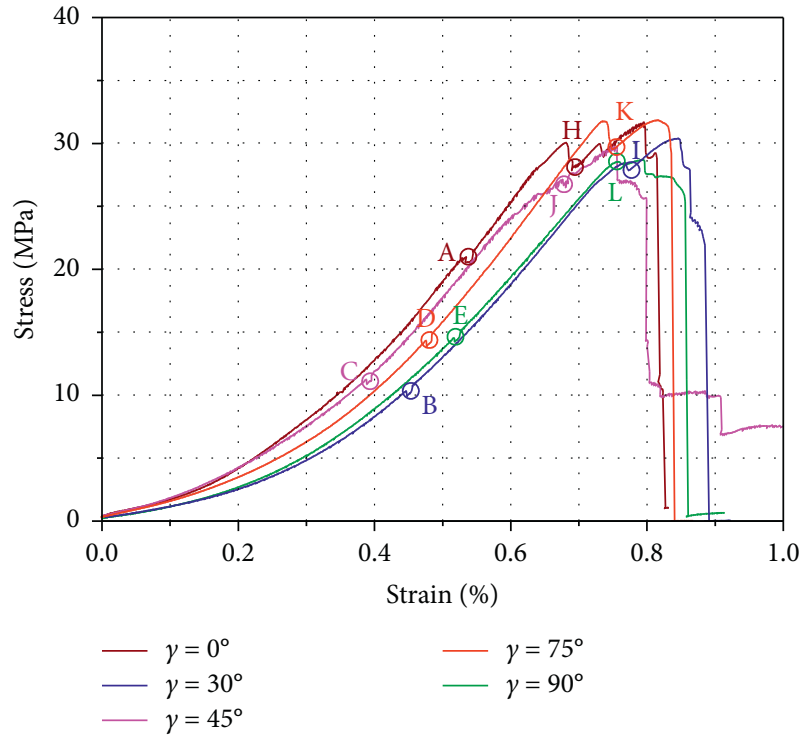

FIGURE 14: Stress-strain curves of sandy mudstone specimens for different angles between main and minor flaws $(\gamma)$.

$\left(\sigma_{\mathrm{cc}} / \sigma_{c}\right)$ ratios obtained with different $\gamma$ are listed in Table 6. The $\left(\sigma_{\mathrm{ci}} / \sigma_{c}\right)$ value is within the range of $0.31-0.51$. The $\left(\sigma_{\mathrm{cc}}\left(\sigma_{c}\right)\right.$ value is between 0.88 and 0.96 , showing minor changes, which indicates that the angle between main and minor flaws has little effect on the crack coalescence stress. The curves of $\gamma$ versus $\left(\sigma_{\mathrm{ci}} / \sigma_{c}\right)$ and $\left(\sigma_{\mathrm{cc}} / \sigma_{c}\right)$ are shown in Figure 15.

The $\left(\sigma_{\mathrm{ci}} / \sigma_{c}\right)$ and $\left(\sigma_{\mathrm{cc}} / \sigma_{c}\right)$ ratios increase with the increasing angle $\gamma$. For $\gamma=0^{\circ}$, the main flaw overlaps with the minor flaw, and there are only two parallel flaws in each rock specimen. In this case, the $\left(\sigma_{\mathrm{ci}} / \sigma_{c}\right)$ ratio is the highest, which indicates the crack initiation is closest to the peak stress and the initiation is more difficult for non-cross-flaws than for cross-flaws. When $\gamma$ is not 0 , the main flaw is crossed by the minor flaw, and the $\left(\sigma_{\mathrm{ci}} / \sigma_{c}\right)$ ratio increases with increasing angle. The lowest $\left(\sigma_{\mathrm{ci}} / \sigma_{c}\right)$ ratio is obtained for $\gamma=30^{\circ}$, which means the crack initiation is the earliest and easiest. The $\left(\sigma_{\mathrm{cc}} / \sigma_{c}\right)$ ratio has little change when $\gamma$ varies from $30^{\circ}$ to $75^{\circ}$, whereas a maximum is observed for $\gamma=90^{\circ}$. This trend indicates that increasing the angle between main and minor flaws has little effect on crack coalescence stress; however, the coalescence stress reaches its maximum when the main and minor flaws are perpendicular to each other. This is in agreement with our experimental observation (Figure 6(d)) that the cracks are first initiated at the tips of the main and minor flaws, and only after they are linked, crack coalescence occurs between the two sets of main and minor flaws.

\section{Conclusions}

In this study, uniaxial compression tests were performed on sandy mudstone specimens containing two sets of crossflaws. The experimental processes were simulated by the FJM model based on PFC2D numerical simulation. Then, the effects of two geometric parameters on crack propagation, initiation stress, and coalescence stress were analyzed. The
TABLE 6: The crack initiation and coalescence stress (c) for different angles between main and minor flaws $(\gamma)$.

\begin{tabular}{lccccc}
\hline$\gamma\left({ }^{\circ}\right)$ & $\sigma_{\mathrm{ci}}(\mathrm{MPa})$ & $\sigma_{\mathrm{cc}}(\mathrm{MPa})$ & $\sigma_{c}(\mathrm{MPa})$ & $\left(\sigma_{\mathrm{ci}} / \sigma_{c}\right)$ & $\left(\sigma_{\mathrm{cc}} / \sigma_{c}\right)$ \\
\hline 0 & 21.03 & 27.87 & 31.77 & 0.66 & 0.88 \\
30 & 10.40 & 27.75 & 30.53 & 0.34 & 0.90 \\
45 & 11.15 & 27.14 & 29.82 & 0.37 & 0.91 \\
75 & 10.81 & 22.13 & 24.02 & 0.45 & 0.92 \\
90 & 14.69 & 27.53 & 28.80 & 0.51 & 0.96 \\
\hline
\end{tabular}

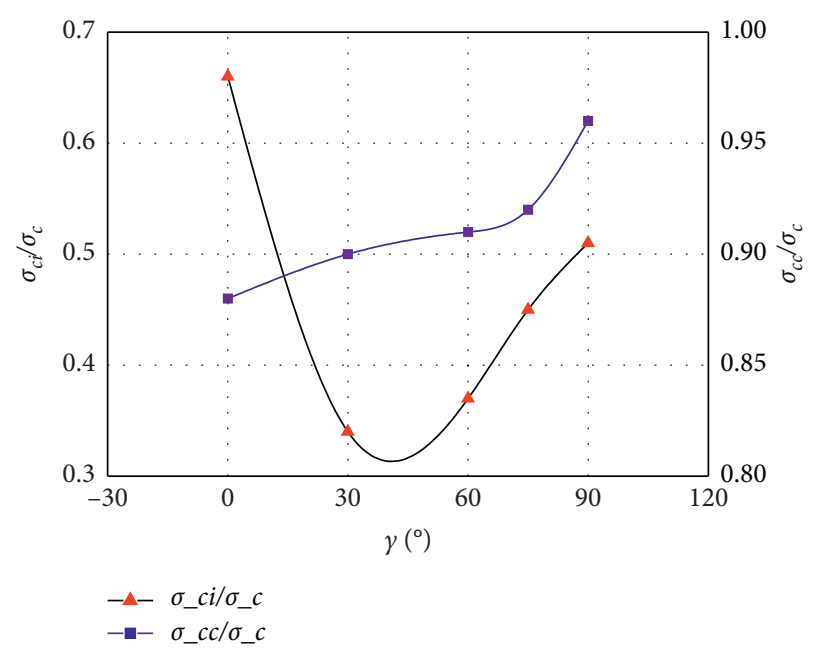

FIgURE 15: The angle between main and minor flaws $(\gamma)$ versus crack initiation and coalescence stress $\left(\left(\sigma_{\mathrm{ci}} / \sigma_{c}\right)\right.$ and $\left.\left(\sigma_{\mathrm{cc}} / \sigma_{c}\right)\right)$.

results indicate that the FJM model is robust to simulate the processes of crack initiation, propagation, and coalescence in sandy mudstone specimens. The key conclusions of this study are given below:

(1) In the rock specimens with prefabricated cross-flaws, type III tensile cracks are the first cracks initiated in physical experiments and FJM simulation.

(2) The dip of the rock bridge with main flaw $(\beta)$ have strong effects on crack initiation and coalescence stress. The initiation and coalescence stresses increase first and then decrease with the increasing angle $(\beta)$ in a parabolic pattern. Moreover, increasing the angle between main and minor flaws $(\gamma)$ results in higher crack initiation and coalescence stress, and the initiation force is reduced for crossflaws compared with non-cross-flaws.

(3) The angle $(\beta)$ is the most influential geometric parameter for the rock failure mode and crack initiation, propagation, and coalescence. By comparison, the angle $(\gamma)$ has less effect on crack coalescence and failure mode.

\section{Data Availability}

The data used to support the findings of this study are available from the corresponding author upon request. 


\section{Conflicts of Interest}

The authors declare that they have no conflicts of interest.

\section{Acknowledgments}

This work was supported by the National Natural Science Foundation of China (52034007 and 52074263) and National Key Research and Development Plan (2017YFC0603001).

\section{References}

[1] J. Zhang, F. Jiang, J. Yang, W. Bai, and L. Zhang, "Rockburst mechanism in soft coal seam within deep coal mines," International Journal of Mining Science and Technology, vol. 27, no. 3, pp. 551-556, 2017.

[2] Y. T. Sun, G. Li, H. Basarir, A. Karrech, and M. Reza Azadi, "Laboratory evaluation of shear strength properties for cement-based grouted coal mass," Arabian Journal of Geosciences, vol. 12, no. 22, p. 690, 2019.

[3] C. H. Park and A. Bobet, "Crack initiation, propagation and coalescence from frictional flaws in uniaxial compression," Engineering Fracture Mechanics, vol. 77, no. 14, pp. 27272748, 2010.

[4] L. N. Y. Wong and H. H. Einstein, "Systematic evaluation of cracking behavior in specimens containing single flaws under uniaxial compression," International Journal of Rock Mechanics and Mining Sciences, vol. 46, no. 2, pp. 239-249, 2009.

[5] P. Cao, T. Liu, C. Pu, and H. Lin, "Crack propagation and coalescence of brittle rock-like specimens with pre-existing cracks in compression," Engineering Geology, vol. 187, pp. 113-121, 2015.

[6] R. H. C. Wong, K. T. Chau, C. A. Tang, and P. Lin, "Analysis of crack coalescence in rock-like materials containing three flaws-part I: experimental approach," International Journal of Rock Mechanics and Mining Sciences, vol. 38, no. 7, pp. 909-924, 2001.

[7] B. Shen and O. Stephansson, "Modification of the G-criterion for crack propagation subjected to compression," Engineering Fracture Mechanics, vol. 47, no. 2, pp. 177-189, 1994.

[8] A. Bobet, "The initiation of secondary cracks in compression," Engineering Fracture Mechanics, vol. 66, no. 2, pp. 187-219, 2000.

[9] H. Lee and S. Jeon, "An experimental and numerical study of fracture coalescence in pre-cracked specimens under uniaxial compression," International Journal of Solids and Structures, vol. 48, no. 6, pp. 979-999, 2011.

[10] R. H. C. Wong and K. T. Chau, "Crack coalescence in a rocklike material containing two cracks," International Journal of Rock Mechanics and Mining Sciences, vol. 35, no. 2, pp. 147-164, 1998.

[11] M. Sagong, "Coalescence of multiple flaws in a rock-model material in uniaxial compression," International Journal of Rock Mechanics and Mining Sciences, vol. 39, no. 2, pp. 229-241, 2002.

[12] L. N. Y. Wong and H. H. Einstein, "Crack coalescence in molded gypsum and carrara marble: Part 1. Macroscopic observations and interpretatio," Rock Mechanics and Rock Engineering, vol. 42, no. 3, pp. 475-511, 2008.

[13] C. H. Park and A. Bobet, "Crack coalescence in specimens with open and closed flaws: a comparison," International Journal of Rock Mechanics and Mining Sciences, vol. 46, no. 5, pp. 819-829, 2009.
[14] P. Yin, R. H. C. Wong, and K. T. Chau, "Coalescence of two parallel pre-existing surface cracks in granite," International Journal of Rock Mechanics and Mining Sciences, vol. 68, pp. 66-84, 2014.

[15] A. Modiriasari, A. Bobet, and L. J. Pyrak-Nolte, "Active seismic monitoring of crack initiation, propagation, and coalescence in rock," Rock Mechanics and Rock Engineering, vol. 50, no. 9, pp. 2311-2325, 2017.

[16] E. Hoek and Z. T. Bieniawski, "Brittle fracture propagation in rock under compression," International Journal Fracture Mechanics, vol. 1, no. 3, pp. 137-155, 1965.

[17] D. Huang, D. Gu, C. Yang, R. Huang, and G. Fu, "Investigation on mechanical behaviors of sandstone with two preexisting flaws under triaxial compression," Rock Mechanics and Rock Engineering, vol. 49, no. 2, pp. 375-399, 2015.

[18] D. Q. Dan and H. Konietzky, "Numerical simulations and interpretations of Brazilian tensile tests on transversely isotropic rocks," International Journal of Rock Mechanics and Mining Sciences, vol. 71, pp. 53-63, 2014.

[19] H. Haeri, K. Shahriar, M. F. Marji, and P. Moarefvand, "Experimental and numerical study of crack propagation and coalescence in pre-cracked rock-like disks," International Journal of Rock Mechanics and Mining Sciences, vol. 67, pp. 20-28, 2014.

[20] X.-P. Zhou, X.-B. Gu, and Y.-T. Wang, "Numerical simulations of propagation, bifurcation and coalescence of cracks in rocks," International Journal of Rock Mechanics and Mining Sciences, vol. 80, pp. 241-254, 2015.

[21] G. Xu, C. He, Z. Chen, and A. Su, "Transverse isotropy of phyllite under Brazilian tests: laboratory testing and numerical simulations," Rock Mechanics and Rock Engineering, vol. 51, no. 4, pp. 1111-1135, 2017.

[22] P. Wang, M. Cai, and F. Ren, "Anisotropy and directionality of tensile behaviours of a jointed rock mass subjected to numerical Brazilian tests," Tunnelling and Underground Space Technology, vol. 73, pp. 139-153, 2018.

[23] X.-X. Yang and W.-G. Qiao, "Numerical investigation of the shear behavior of granite materials containing discontinuous joints by utilizing the flat-joint model," Computers and Geotechnics, vol. 104, pp. 69-80, 2018.

[24] S.-Q. Yang, Y.-H. Huang, W.-L. Tian, and J.-B. Zhu, "An experimental investigation on strength, deformation and crack evolution behavior of sandstone containing two oval flaws under uniaxial compression," Engineering Geology, vol. 217, pp. 35-48, 2017.

[25] D. Li, Q. Zhu, Z. Zhou, X. Li, and P. G. Ranjith, "Fracture analysis of marble specimens with a hole under uniaxial compression by digital image correlation," Engineering Fracture Mechanics, vol. 183, pp. 109-124, 2017.

[26] F. Erdogan and G. C. Sih, "Closure to "discussion of "on the crack extension in plates under plane loading and transverse shear"” (1963, ASME J. Basic eng., 85, pp. 525-527)," Journal of Basic Engineering, vol. 85, no. 4, p. 527, 1963.

[27] S. K. Maiti and R. A. Smith, "Comparison of the criteria for mixed mode brittle fracture based on the preinstability stressstrain field part I: slit and elliptical cracks under uniaxial tensile loading," International Journal of Fracture, vol. 23, no. 4, pp. 281-295, 1983.

[28] X. M. Kong, N. Schlüter, and W. Dahl, "Effect of triaxial stress on mixed-mode fracture," Engineering Fracture Mechanics, vol. 52, no. 2, pp. 379-388, 1995.

[29] A. Bobet and H. H. Einstein, "Fracture coalescence in rock material under uniaxial and biaxial loading," Key Engineering Materials, vol. 183-187, no. 187, pp. 809-814, 1996. 
[30] B. Antonio, "Fracture coalescence in rock materials: experimental observations and numerical predictions," Ph.D. thesis, Massachusetts Institute of Technology, Cambridge, MA, USA, 1997.

[31] A. Bobet and H. H. Einstein, "Fracture coalescence in rocktype materials under uniaxial and biaxial compression," International Journal of Rock Mechanics and Mining Sciences, vol. 35, no. 7, pp. 863-888, 1998.

[32] J. R. Rice, "A path independent integral and the approximate analysis of strain concentration by notches and cracks," Journal of Applied Mechanics, vol. 35, no. 2, pp. 379-386, 1967.

[33] G. R. Irwin, "Strain energy release rate for a crack under combined mode I and mode II," in STP560-EB Fracture Analysis: Proceedings of the 1973 National Symposium on Fracture Mechanics, Part II, pp. 2-28, ASTM International, West Conshohocken, PA, USA, 1973.

[34] G. C. Sih, "Strain-energy-density factor applied to mixed mode crack problems," International Journal of Fracture, vol. 10, no. 3, pp. 305-321, 1974.

[35] P. S. Theocaris, "The T-criterion applied to ductile fracture," International Journal of Fracture, vol. 20, no. 20, pp. R125R130, 1982.

[36] P. S. Theocaris and N. P. Andrianopoulos, "The mises elasticplastic boundary as the core region in fracture criteria," Engineering Fracture Mechanics, vol. 16, no. 3, pp. 425-432, 1982.

[37] P. S. Theocaris, G. A. Kardomateas, and N. P. Andrianopoulos, "Experimental study of the T-criterion in ductile fractures," Engineering Fracture Mechanics, vol. 17, no. 5, pp. 439-447, 1983.

[38] A. A. Wells, "Application of fracture mechanics at and beyond general yield,” British Welding Journal, vol. 10, pp. 563-570, 1963.

[39] O. Reyes and H. H. Einstein, "Failure mechanisms of fractured rock: a fracture coalescence model," in Proceedings of the 7th ISRM Congress, p. 1, Aachen, Germany, September 1991.

[40] S. M. A. Khan and M. K. Khraisheh, "Analysis of mixed mode crack initiation angles under various loading conditions," Engineering Fracture Mechanics, vol. 67, no. 5, pp. 397-419, 2000.

[41] D. Li, J. Zhang, Y. Sun, and G. Li, "Evaluation of rockburst hazard in deep coalmines with large protective island coal pillars," Natural Resources Research, p. 13. In press.

[42] D. O. Potyondy and P. A. Cundall, "A bonded-particle model for rock," International Journal of Rock Mechanics and Mining Sciences, vol. 41, no. 8, pp. 1329-1364, 2004.

[43] X.-P. Zhang and L. N. Y. Wong, "Cracking processes in rocklike material containing a single flaw under uniaxial compression: a numerical study based on parallel bonded-particle model approach," Rock Mechanics and Rock Engineering, vol. 45, pp. 711-737, 2012.

[44] A. Manouchehrian and M. F. Marji, "Numerical analysis of confinement effect on crack propagation mechanism from a flaw in a pre-cracked rock under compression," Acta Mechanica Sinica, vol. 28, no. 5, pp. 1389-1397, 2012.

[45] X.-P. Zhang and L. N. Y. Wong, "Crack initiation, propagation and coalescence in rock-like material containing two flaws: a numerical study based on bonded-particle model approac," Rock Mechanics and Rock Engineering, vol. 46, no. 5, pp. 1001-1021, 2012.

[46] M. Bahaaddini, G. Sharrock, and B. K. Hebblewhite, "Numerical investigation of the effect of joint geometrical parameters on the mechanical properties of a non-persistent jointed rock mass under uniaxial compression," Computers and Geotechnics, vol. 49, pp. 206-225, 2013.

[47] $\mathrm{S}$. Wu and $\mathrm{X}$. Xu, "A study of three intrinsic problems of the classic discrete element method using flat-joint model," Rock Mechanics and Rock Engineering, vol. 49, no. 5, pp. 1813-1830, 2015.

[48] H. Li and L. N. Y. Wong, "Influence of flaw inclination angle and loading condition on crack initiation and propagation," International Journal of Solids and Structures, vol. 49, no. 18, pp. 2482-2499, 2012.

[49] E. T. Brown, "Rock Characterization, Testing \& Monitoring: ISRM Suggested Methods," Pergamon Press, London, UK, 1981.

[50] D. O. Potyondy, "A flat-jointed bonded-particle material for hard rock," in in Proceedings of the 46th US Rock Mechanics/ Geomechanics Symposium, Chicago, IL, USA, June 2012..

[51] D. Xiao-bin, L. Zhang, H. Zhu, and Q. Zhang, "Effect of model scale and particle size distribution on PFC3D simulation results," Rock Mechanics and Rock Engineering, vol. 47, pp. 2139-2156, 2014.

[52] W. F. Brace, B. W. Paulding Jr., and C. Scholz, "Dilatancy in the fracture of crystalline rocks," Journal of Geophysical Research, vol. 71, no. 16, pp. 3939-3953, 1966.

[53] Z. T. Bieniawski, "Mechanism of brittle fracture of rock: part I-theory of the fracture process," International Journal of Rock Mechanics and Mining Sciences \& Geomechanics Abstracts, vol. 4, no. 4, pp. 395-406, 1967.

[54] D. J. Holcomb and L. S. Costin, "Damage in brittle materials: experimental methods," in Proceedings of the 10th U.S. National Congress of Applied Mechanics, Austin, TX, USA, June 1986.

[55] C. D. Martin, “The strength of massive Lac du Bonnet granite around underground openings," Ph.D. thesis, University of Manitoba, Winnipeg, Canada, 1993. 